NASA/TM-2004-212915

\title{
Controls and Health Management Technologies for Intelligent Aerospace Propulsion Systems
}

Sanjay Garg

Glenn Research Center, Cleveland, Ohio 
Since its founding, NASA has been dedicated to the advancement of aeronautics and space science. The NASA Scientific and Technical Information (STI) Program Office plays a key part in helping NASA maintain this important role.

The NASA STI Program Office is operated by Langley Research Center, the Lead Center for NASA's scientific and technical information. The NASA STI Program Office provides access to the NASA STI Database, the largest collection of aeronautical and space science STI in the world. The Program Office is also NASA's institutional mechanism for disseminating the results of its research and development activities. These results are published by NASA in the NASA STI Report Series, which includes the following report types:

- TECHNICAL PUBLICATION. Reports of completed research or a major significant phase of research that present the results of NASA programs and include extensive data or theoretical analysis. Includes compilations of significant scientific and technical data and information deemed to be of continuing reference value. NASA's counterpart of peerreviewed formal professional papers but has less stringent limitations on manuscript length and extent of graphic presentations.

- TECHNICAL MEMORANDUM. Scientific and technical findings that are preliminary or of specialized interest, e.g., quick release reports, working papers, and bibliographies that contain minimal annotation. Does not contain extensive analysis.

- CONTRACTOR REPORT. Scientific and technical findings by NASA-sponsored contractors and grantees.
- CONFERENCE PUBLICATION. Collected papers from scientific and technical conferences, symposia, seminars, or other meetings sponsored or cosponsored by NASA.

- SPECIAL PUBLICATION. Scientific, technical, or historical information from NASA programs, projects, and missions, often concerned with subjects having substantial public interest.

- TECHNICAL TRANSLATION. Englishlanguage translations of foreign scientific and technical material pertinent to NASA's mission.

Specialized services that complement the STI Program Office's diverse offerings include creating custom thesauri, building customized databases, organizing and publishing research results ... even providing videos.

For more information about the NASA STI Program Office, see the following:

- Access the NASA STI Program Home Page at http://www.sti.nasa.gov

- E-mail your question via the Internet to help@sti.nasa.gov

- Fax your question to the NASA Access Help Desk at 301-621-0134

- Telephone the NASA Access Help Desk at 301-621-0390

- Write to:

NASA Access Help Desk

NASA Center for AeroSpace Information 7121 Standard Drive

Hanover, MD 21076 
NASA/TM-2004-212915

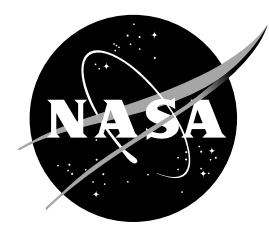

\section{Controls and Health Management Technologies for Intelligent Aerospace Propulsion Systems}

Sanjay Garg

Glenn Research Center, Cleveland, Ohio

Prepared for the

42nd Aerospace Sciences Meeting and Exhibit

sponsored by the American Institute of Aeronautics and Astronautics

Reno, Nevada, January 5-8, 2004

National Aeronautics and

Space Administration

Glenn Research Center 


\section{Acknowledgments}

The author would like to thank all the members of the Control and Dynamics Technology Branch for their enthusiasm and initiative in performing the research documented in this paper, and for providing the graphics for the paper.

Available from

NASA Center for Aerospace Information 7121 Standard Drive

Hanover, MD 21076
National Technical Information Service 5285 Port Royal Road Springfield, VA 22100

Available electronically at http:/ /gltrs.grc.nasa.gov 


\title{
Controls and Health Management Technologies for Intelligent Aerospace Propulsion Systems
}

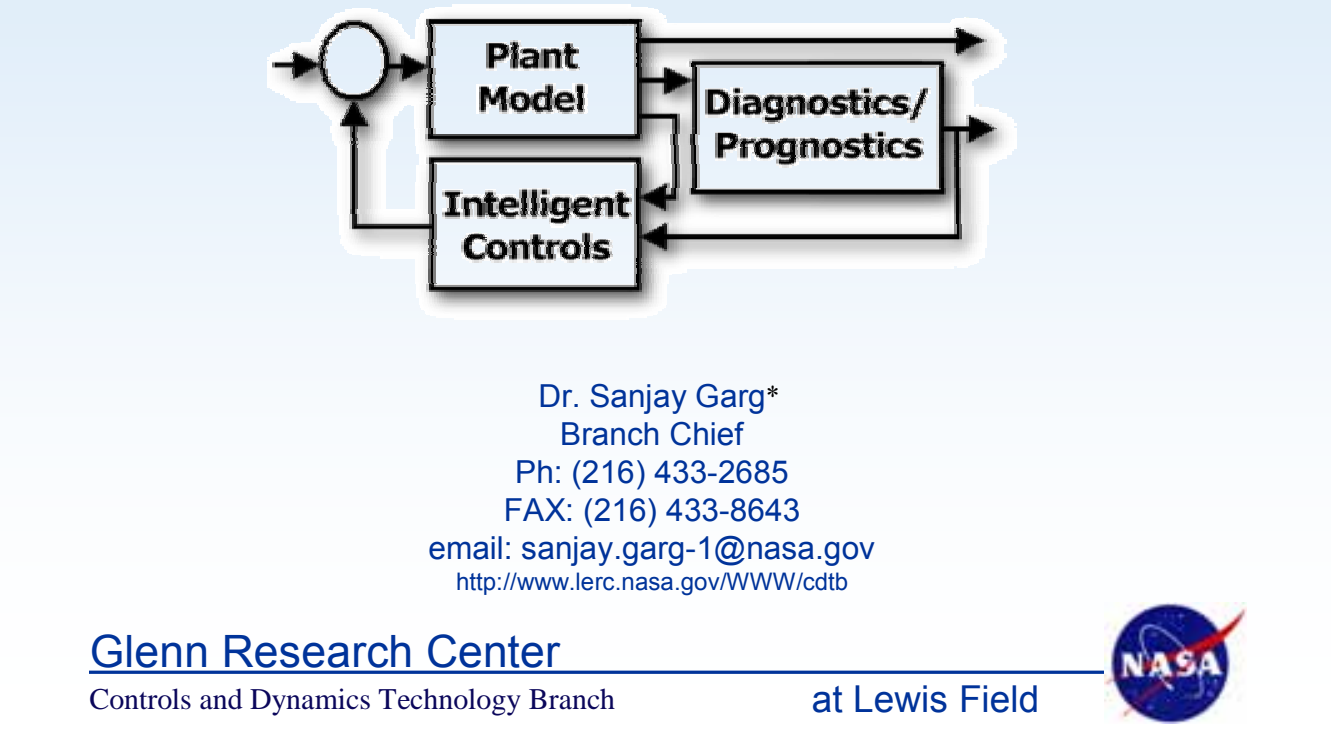

\begin{abstract}
With the increased emphasis on aircraft safety, enhanced performance and affordability, and the need to reduce the environmental impact of aircraft, there are many new challenges being faced by the designers of aircraft propulsion systems. The Controls and Dynamics Technology Branch at NASA (National Aeronautics and Space Administration) Glenn Research Center (GRC) in Cleveland, Ohio, is leading and participating in various projects in partnership with other organizations within GRC and across NASA, the U.S. aerospace industry, and academia to develop advanced controls and health management technologies that will help meet these challenges through the concept of an Intelligent Engine. The key enabling technologies for an Intelligent Engine are the increased efficiencies of components through active control, advanced diagnostics and prognostics integrated with intelligent engine control to enhance component life, and distributed control with smart sensors and actuators in an adaptive fault tolerant architecture. This paper describes the current activities of the Controls and Dynamics Technology Branch in the areas of active component control and propulsion system intelligent control, and presents some recent analytical and experimental results in these areas.
\end{abstract}




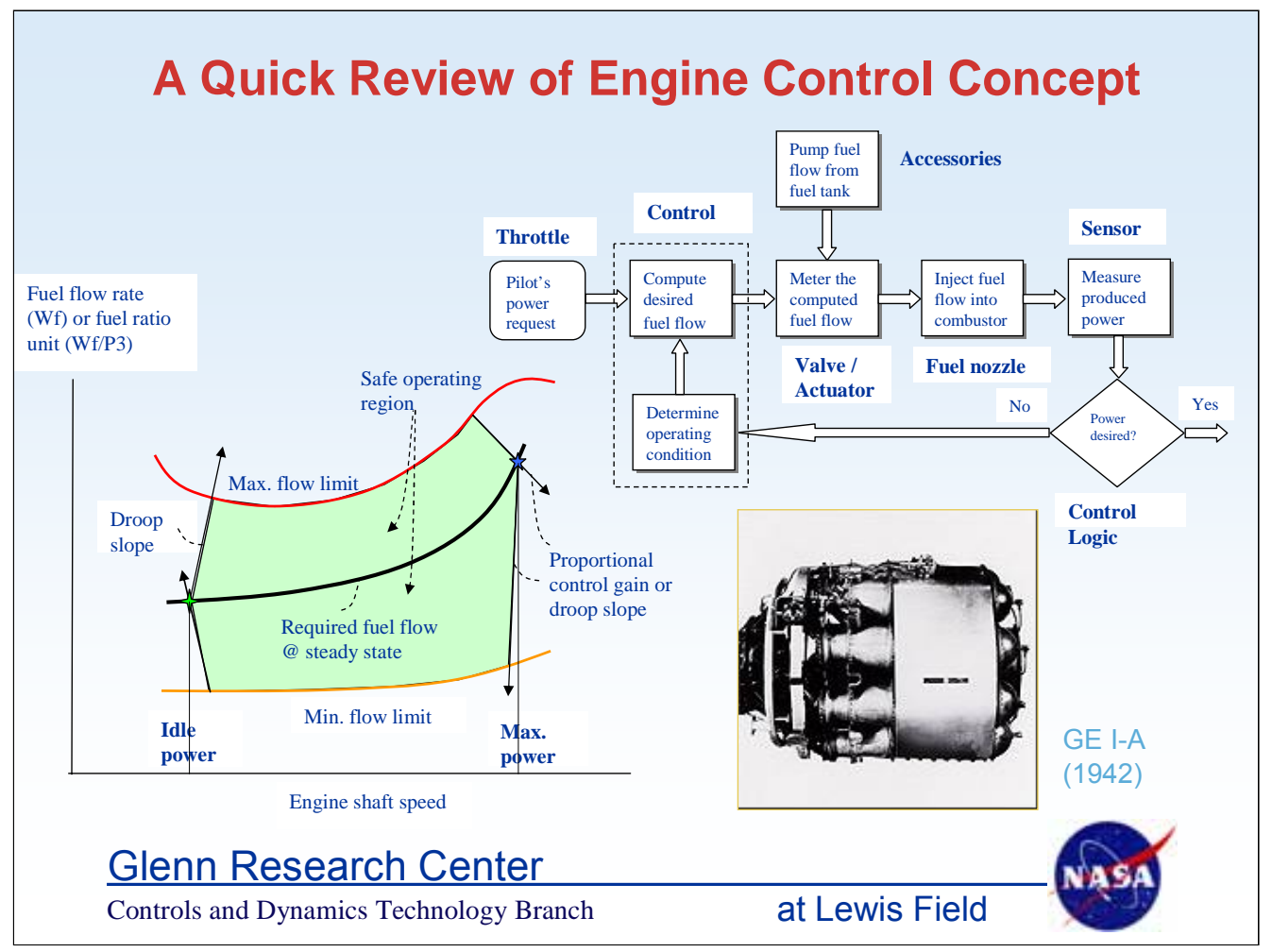

\section{Propulsion Control Background}

A simple engine control system computes the amount of fuel needed for the engine to produce a desired power (or thrust), based on pilot's power request through a throttle (or a power lever); then it meters the right amount of fuel to the engine's combustion chamber(s); and it maintains the engine power at the desired level in the presence of air flow disturbance and changes in flight conditions. The block diagram above illustrates this fuel control system. In-flight engine thrust measurements are not possible. Good indicators of thrust, that have been used successfully, are engine shaft rotational speed $(\mathrm{N})$ or engine pressure ratio (EPR).

An aircraft engine is designed to operate in a wide operating envelope in terms of altitude and speed variations. To a control engineer, these challenges are represented on a fuel flow (Wf) versus engine shaft speed (N) graph, or a fuel ratio unit (Wf/P3, where P3 is the compressor exit static pressure) versus speed graph, as shown in the figure above. The control design challenge is then to be able to transition from one operating point to another while staying within the safe operational limits represented by the max. and min. fuel flow limits. The max. flow limit prevents the engine from surge and over-temperature. The min. flow limit prevents the engine from flame-out.

The first U. S. jet engine was built in 1942 by General Electric (GE). The control for the GE I-A was a hydro-mechanical governor, which metered the fuel flow going into the engine to be proportional to the difference between the set speed and the actual speed of the turbine. A minimum-flow stop and a maximum-flow schedule was added to the flow valve. This system possessed the basic functionality of controlling a single-spool turbojet engine.

Ref: Jaw, L.C., and Garg, S., "Propulsion Control Technology Development in the U. S. - A Historical Perspective", ISABE 2003-1186, proceedings of the International Symposium on Air-breathing Engines, Cleveland, OH, Sept. 2003. 


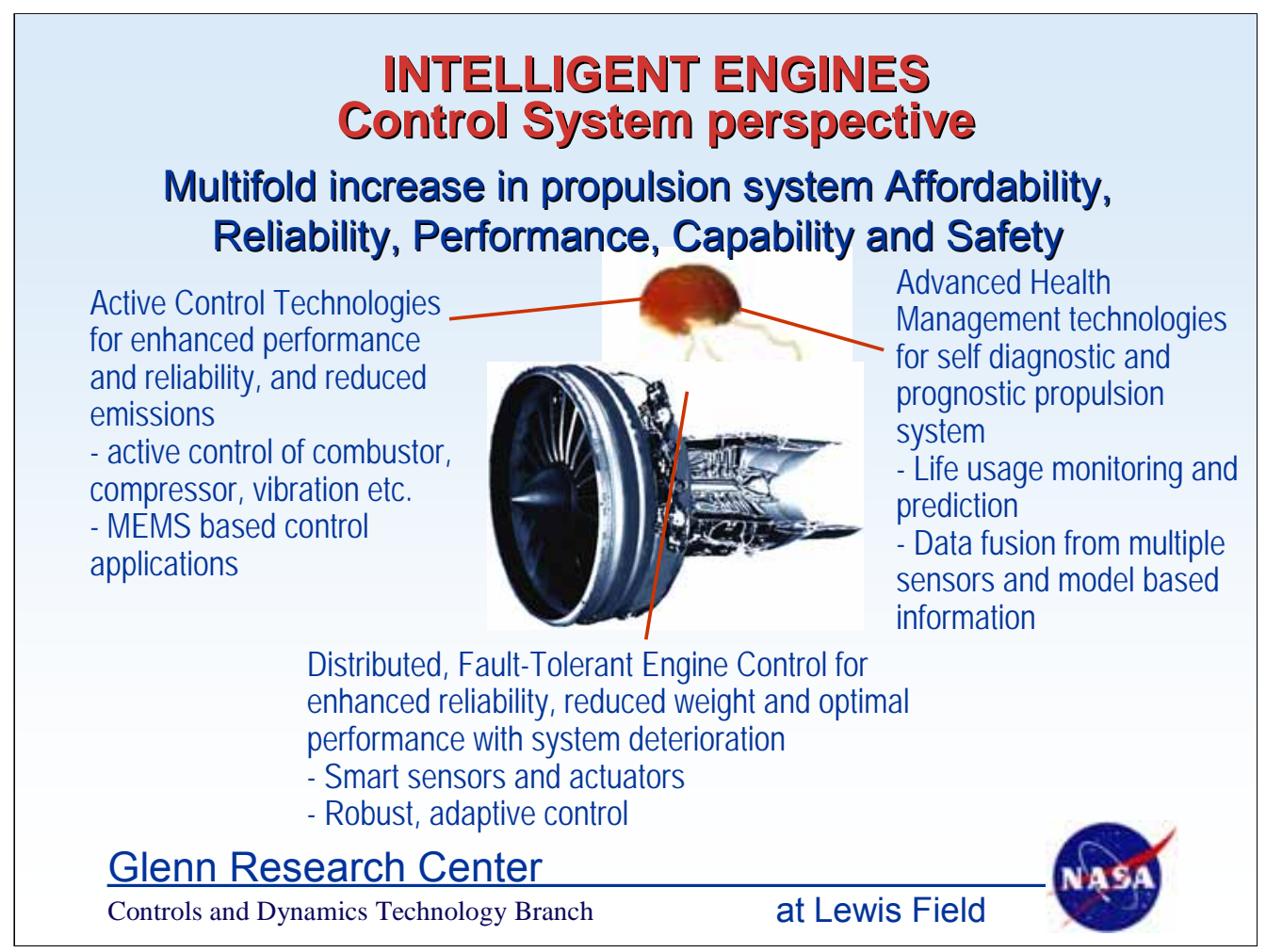

\section{Intelligent Engines - Controls Perspective}

The control system enabling technologies for "Intelligent Engines" can be organized into three broad categories - active component control, advanced health management, and distributed fault tolerant control.

In the past engine components such as combustors, fans and compressors, inlets, nozzles etc. are designed for optimum component performance within some overall system constraints and the control design problem has been to transition the operating point of the engine from one set point to another in a most expedient manner without compromising safety. With the advancements in information technologies, the component designers are beginning to realize the potential of including active control into their component designs to help them meet more stringent design requirements and the need for affordable and environment friendly propulsion systems.

The need to have more reliable and safe engine service, to quickly identify the cause of current or future performance problems and take corrective action, and to reduce the operating cost requires development of advanced diagnostic and prognostic algorithms. The objective for this technology development is to maximize the "on wing" life of the engine and to move from a schedule based maintenance system to a condition based system.

Implementation of of these concepts requires advancements in the area of robust and adaptive control synthesis techniques, and development of new hardware such as smart sensors and actuators. Attention will also need to be paid to integration of the active component control and diagnostics technologies with the control of the overall engine system which will require moving from the current analog control systems to distributed control architectures.

Ref: Garg, S., "Propulsion Control and Health Management Technology Development at NASA Glenn Research Center,” 2002 JANNAF Interagency Propulsion Committee Conference, Destin FL, April 2002. 


\section{CDTB Overview}

- Mission

- Research, develop and verify aerospace propulsion dynamic modeling, health management, control design and implementation technologies that provide advancements in performance, safety, environmental compatibility, reliability and durability

- Facilitate technology insertion into the mainstream aeropropulsion community

- Capabilities

- 20+ engineers and scientists - most with advanced degrees and extensive experience in aeropropulsion controls related fields

- Extensive computer-aided control design and evaluation facilities including real-time and man-in-the-loop simulation facility

- Strong working relationship with controls technology groups in the aerospace propulsion industry, academia and other agencies

Glenn Research Center

Controls and Dynamics Technology Branch

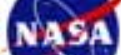

\section{CDTB Overview}

The above figure is self explanatory regarding the capabilities of the Controls and Dynamics Technology Branch. It is important to state here that this paper is not a comprehensive overview of all the propulsion controls related activity at NASA Glenn Research Center. It is primarily meant to focus on the major activities within the Controls and Dynamics Technology Branch which apply to umbrella of "Intelligent Engine" technologies. 


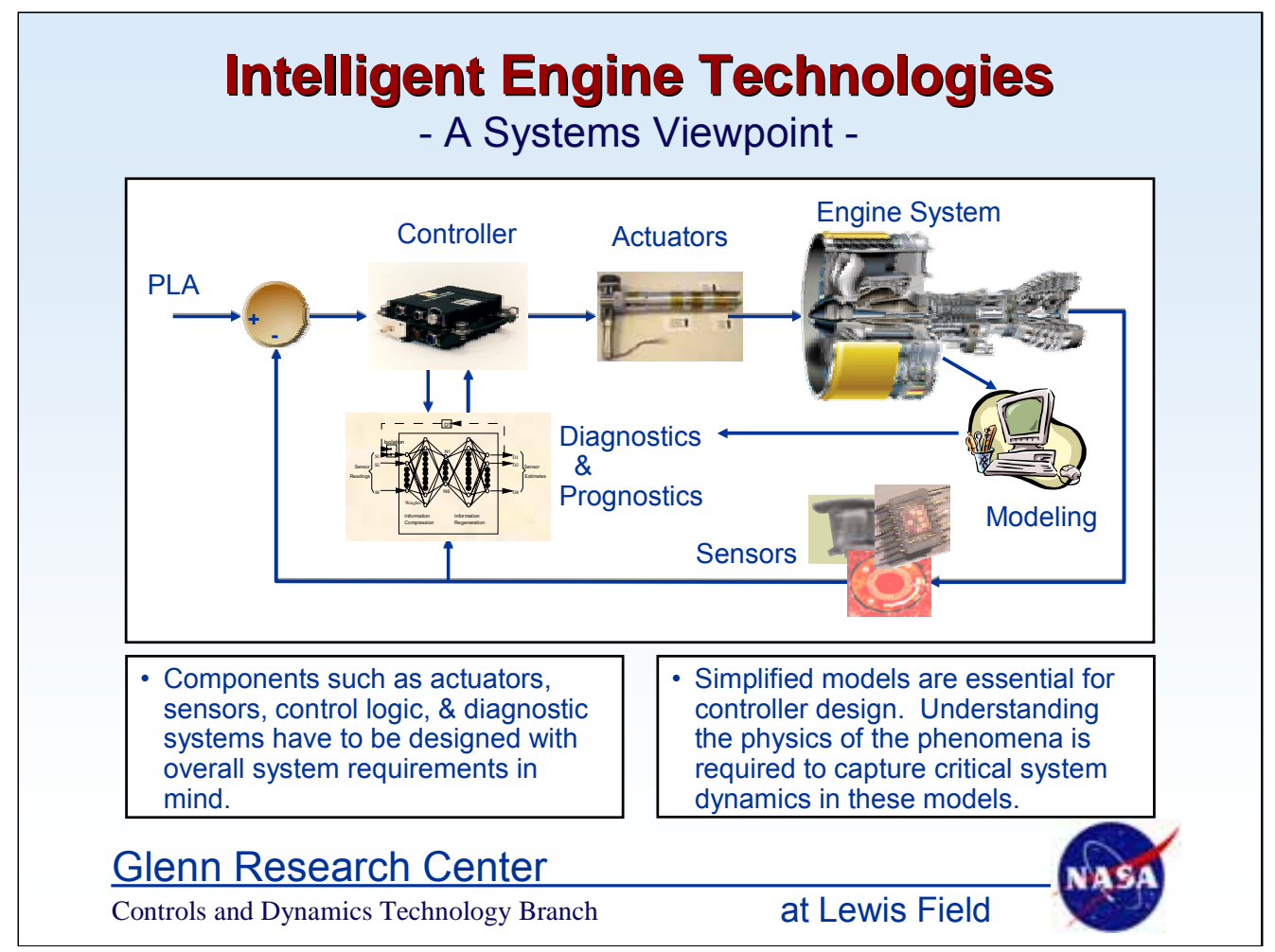

\section{A Systems Perspective}

Although a control system consists of many separate components, such as the actual control hardware and software, an actuation system, a sensing system, on-board models etc., it is important to keep an overall systems perspective in mind when designing these subcomponents.

The CDTB approach to developing a controls technology for "Intelligent Engines" is to start with a good overall understanding of the problem that needs to be addressed. In order to do that we interact with the technology experts in the particular areas that are relevant for that technology. For instance before starting on the task on Intelligent Control of Turbine Tip Clearance, we met with experts in the Turbine, Structures and Materials disciplines to understand what specific problem needed to be addressed, what were the potential benefits of addressing the problem, what is the state-of-theart in terms of sensing and actuation systems available and what type of dynamic models are available and/or need to be developed for control design development and verification.

Starting with simplified computer models which simulate essential dynamics of the problem to be addressed, we then develop some preliminary specifications such as sensor requirements, actuation requirements, and closed-loop system performance requirements. Working in collaboration with our partners within GRC and industry and academia, we develop and implement an integrated task plan which develops the overall technology to the TRL (Technology Readiness Level) that is appropriate for the project that is funding the effort. 


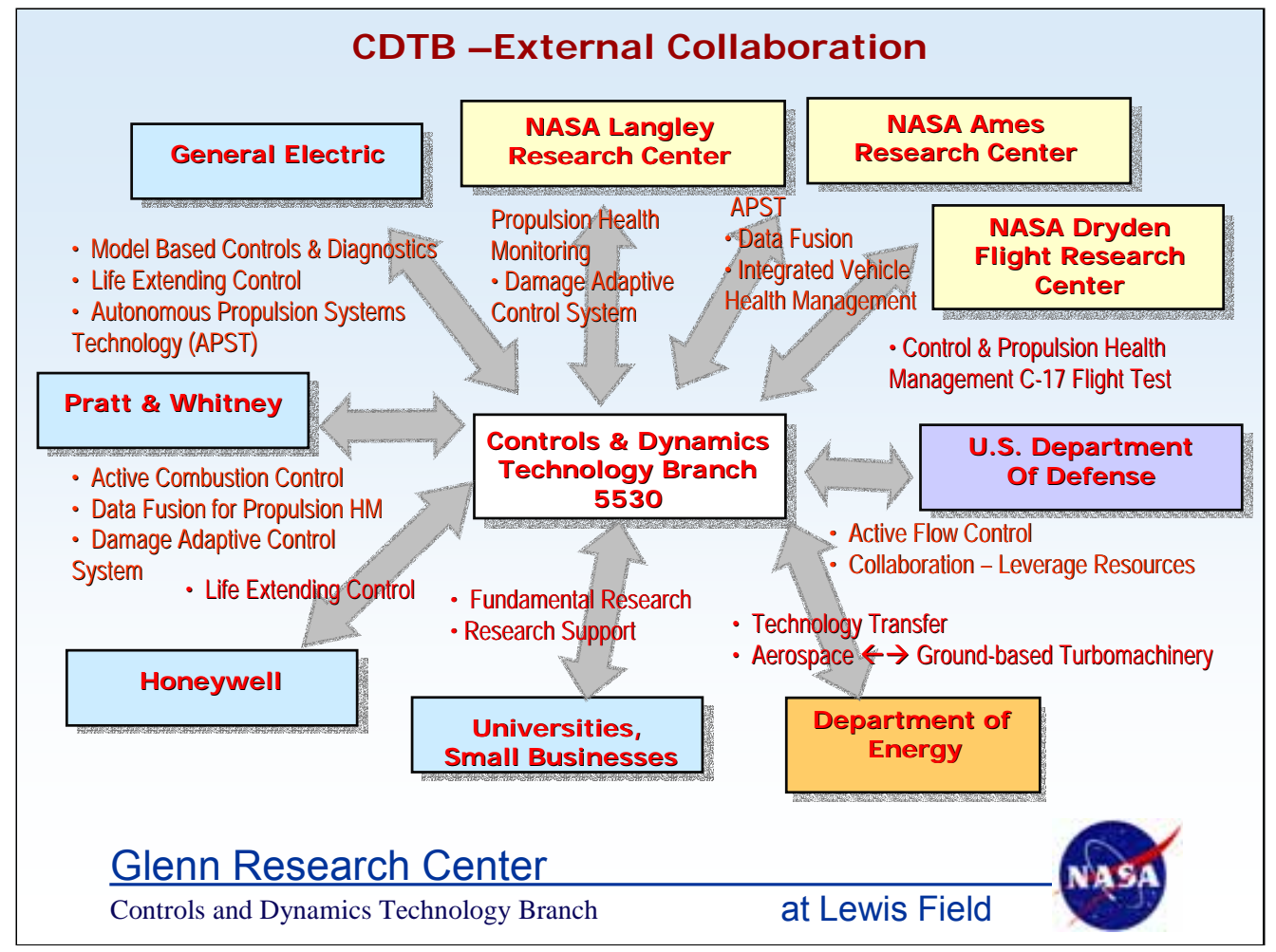

\section{CDTB - External Collaboration}

In addition to the extensive collaboration we have with other groups within GRC to conduct multi-disciplinary research, the Controls and Dynamics Technology Branch works extensively in collaboration with the aerospace propulsion industry to ensure that the technologies being developed are addressing feasible solutions to current problems, or advancing the state of the art of propulsion systems in a way which is compatible with potential transition of technology into future products.

A significant portion of our work is funded by projects which are managed by NASA centers other than Glenn Research Center - such as the work in propulsion health monitoring supported by a Langley led project under the Aviation Safety Program, and the work in Autonomous Propulsion System Technology supported by an Ames led project under the Engineering for Complex Systems program. Additionally we have a strong collaboration with NASA Dryden Flight Research Center in terms of joint planning and implementation of propulsion system flight test program.

We coordinate our activities with various divisions of the Department of Defense (DoD) - Air Force, Navy, Army, DARPA (Defense Advance Research Projects Agency), to ensure that our activities leverage the investments being made by DoD in technology development and that there is no duplication of effort across the government agencies. Additionally we have established collaboration with the FAA (Federal Aviation Administration) through our work on the NASA Aviation Safety program.

We collaborate with universities and small businesses in development and implementation of technologies which are at low levels of TRL (Technology Readiness Level). 


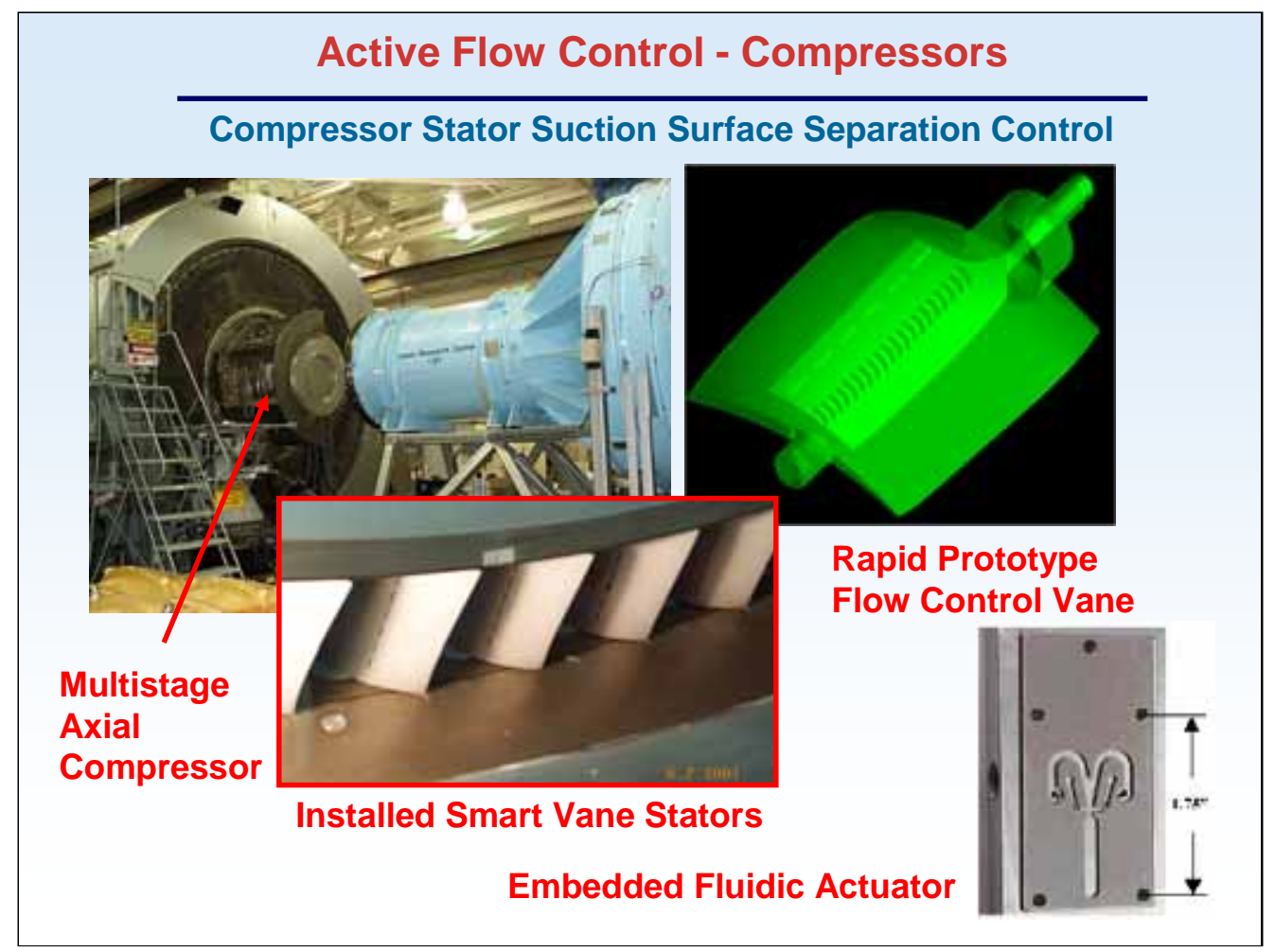

\section{Compressor Flow Control for Increased Efficiency}

One way to achieve greater compression system efficiency is to minimize the pressure loss through the stator. Typical aircraft engines have inlet guide vanes and the incidence angle for these vanes is scheduled based on the engine operating conditions. The actuation system associated with these guide vanes adds weight and complexity to the engine.

The objectives of the compressor flow control research at GRC is to develop and demonstrate flow control methods that utilize air injection in high-speed compressors for control of flow separation within stators. Successful separation control may enable improved performance in two ways: i) by increasing the range of incidence angles over which total pressure loss is acceptable, and ii) by increasing the loading level at which an acceptable level of loss occurs. The tangible benefits may be an increase in operability and an increase in stator aerodynamic loading, which can lead to reduced engine weight and parts count through lower solidity.

The current research is focused on development of stator vane separation control methods using a low speed compressor facility. For durability and ease of maintenance it is desired that there be no moving parts within the vane. Since injected air must be bled from the aft stages of the compressor, it is important to minimize the amount of injection required. Two approaches to making efficient use of air injection for flow separation control are being investigated - i) biased oscillatory injection; ii) active control of injection. The figure above shows a fluidic actuator which is embedded in the vane to provide a biased oscillatory flow. Although this approach requires a more complicated vane fabrication process, it achieves unsteady injection with no moving parts. 


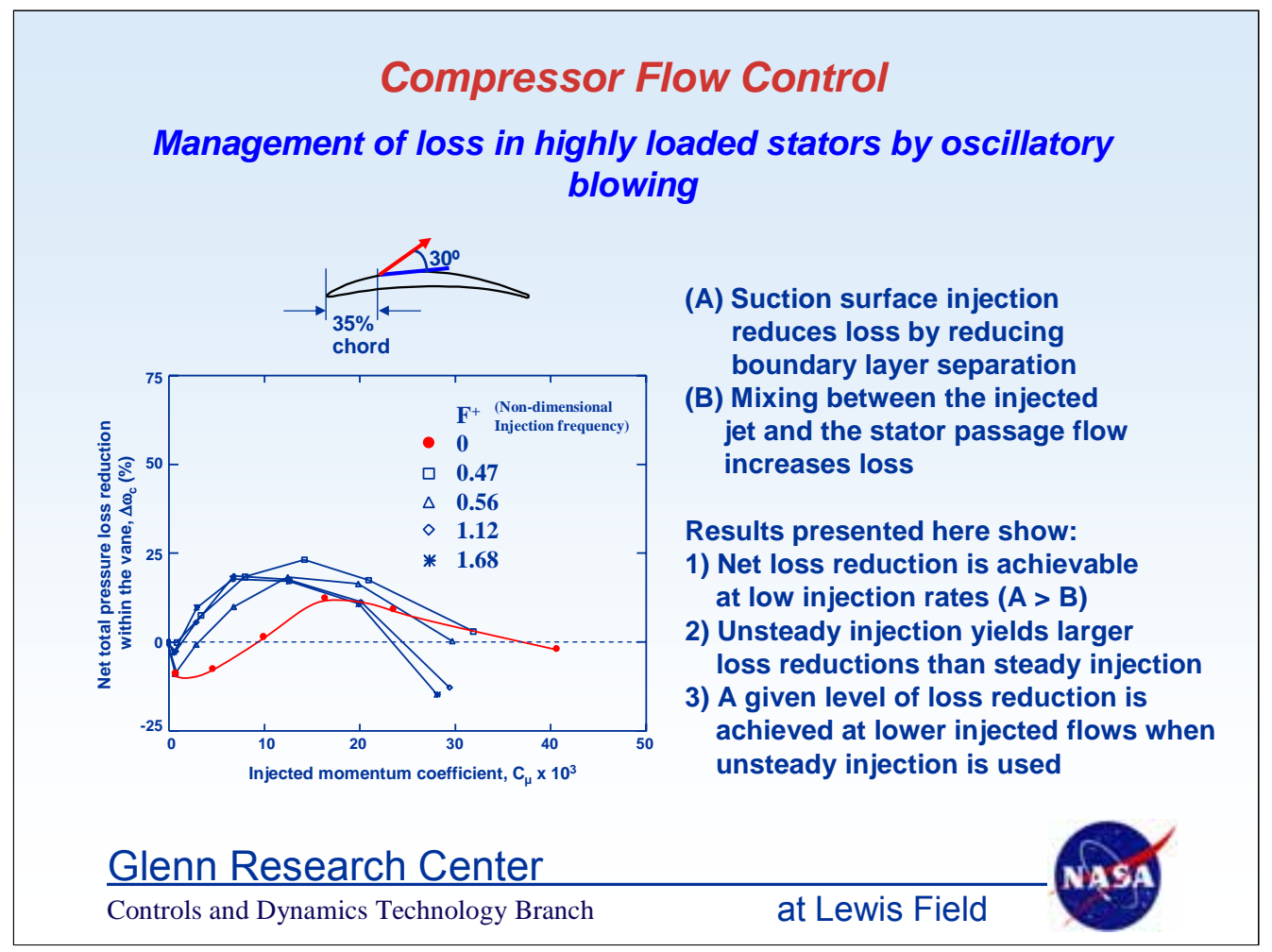

\section{Compressor Flow Control for Increased Efficiency - Recent Results}

The above chart shows some recent results obtained using oscillatory flow control. The results indicate that the net pressure loss is lower with unsteady injection and significant pressure loss reduction can be achieved with very low level of injected flows.

Closed-loop separation control is more desirable because it commands injection only when necessary, thus minimizing the thermodynamic penalty associated with the increased compressor bleed, which is the source of air needed for injection.

However, closed-loop control requires a method of sensing the onset of separation. One way to estimate separation is by instrumenting the vane with static pressure taps along the suction surface. However, such an approach is very costly.

An alternate approach which has been successful in the low speed compressor experiments has been to use a pressure transducer located in the casing next to the vane suction surface at $85 \%$ chord. Further research is continuing using a full row of flow control vanes.

Ref.: Culley, D.E. et al., “Active Flow Separation Control of a Stator Vane using Surface Injection in a Multistage Compressor Experiment”, Paper No. GT200338863, Proceedings of the ASME Turbo Expo 2003, June 16-19, Atlanta, GA. 


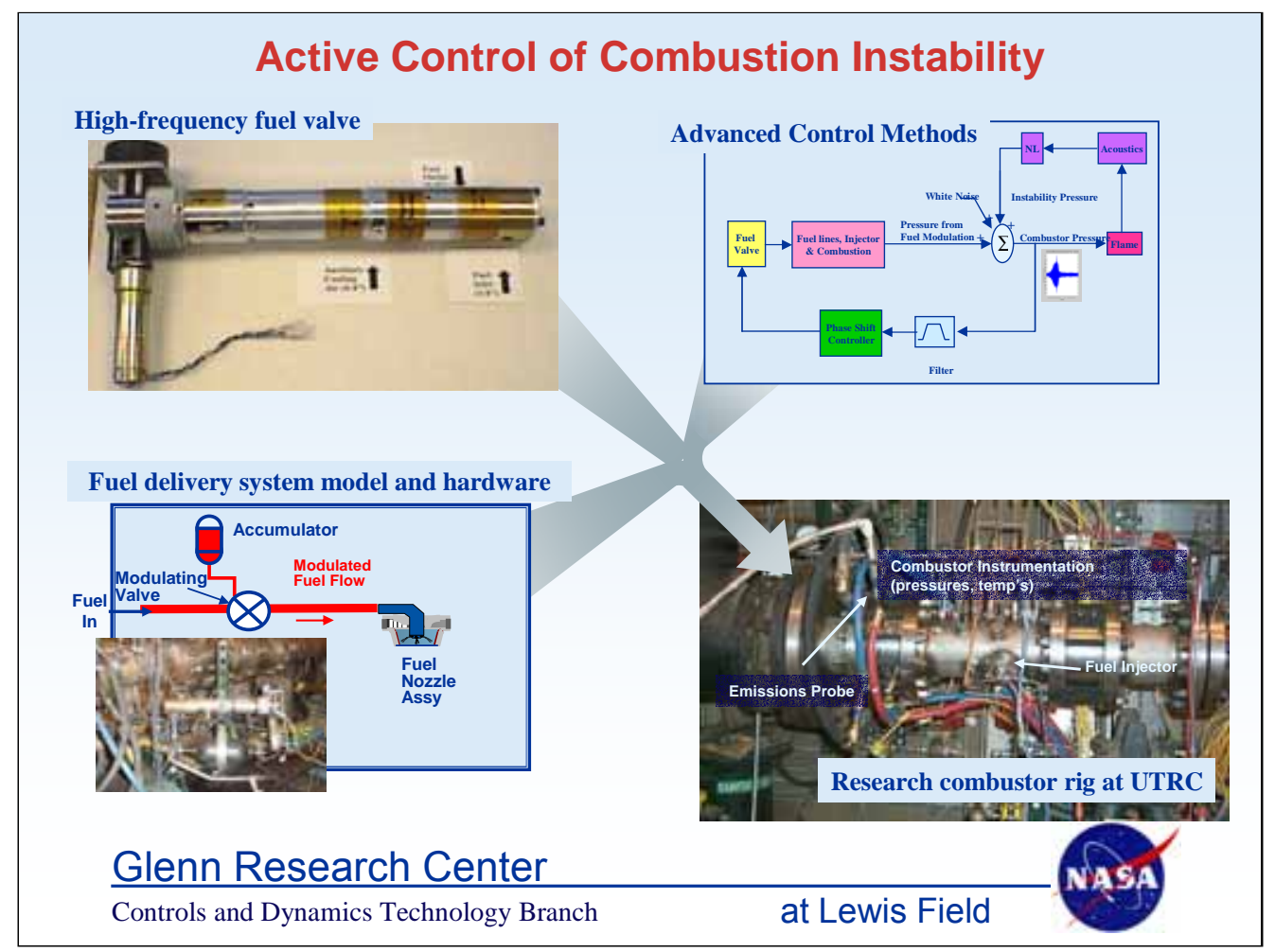

\section{Active Control of Combustion Instability}

As the aircraft engine industry moves towards lean burning combustors in order to meet stringent low-emission requirements, maintaining stability for these combustors can become more problematic. The thermo-acoustic combustion instability issues have already been encountered in lean burning ground-based power generation gas turbine systems. For ground based systems, these issues have been overcome by making ad-hoc design changes. However, dealing with these issues in aero-engines is more challenging since aero-engines operate over a wide range of conditions.

NASA GRC has been working in collaboration with Pratt \& Whitney (P\&W) and United Technologies Research Center (UTRC) to develop and demonstrate technologies for the active suppression of thermo-acoustic instability. As part of this effort, a single nozzle combustor rig was developed at UTRC which has the capability to duplicate the thermo-acoustic instability that was observed in an actual engine test.

In order to suppress instabilities, it is necessary to modulate the fuel flow entering this representative combustor at roughly $600 \mathrm{~Hz}$ (function of combustor length). A valve was developed in conjunction with Georgia Tech which is capable of generating the required high frequency modulations in fuel flow. An actuator characterization rig was built up at GRC to be able to identify the dynamic characteristics of the valve so that the actuator models can be used for control design development.

Another critical component is the fuel delivery system. An improperly designed fuel delivery system can attenuate perturbations generated by the valve and render the control system ineffective. The fuel delivery system was modeled to better understand these attenuation effects, and open loop testing of the high frequency actuator in the combustion rig is currently being conducted to ensure adequate effectiveness of fuel modulation. 


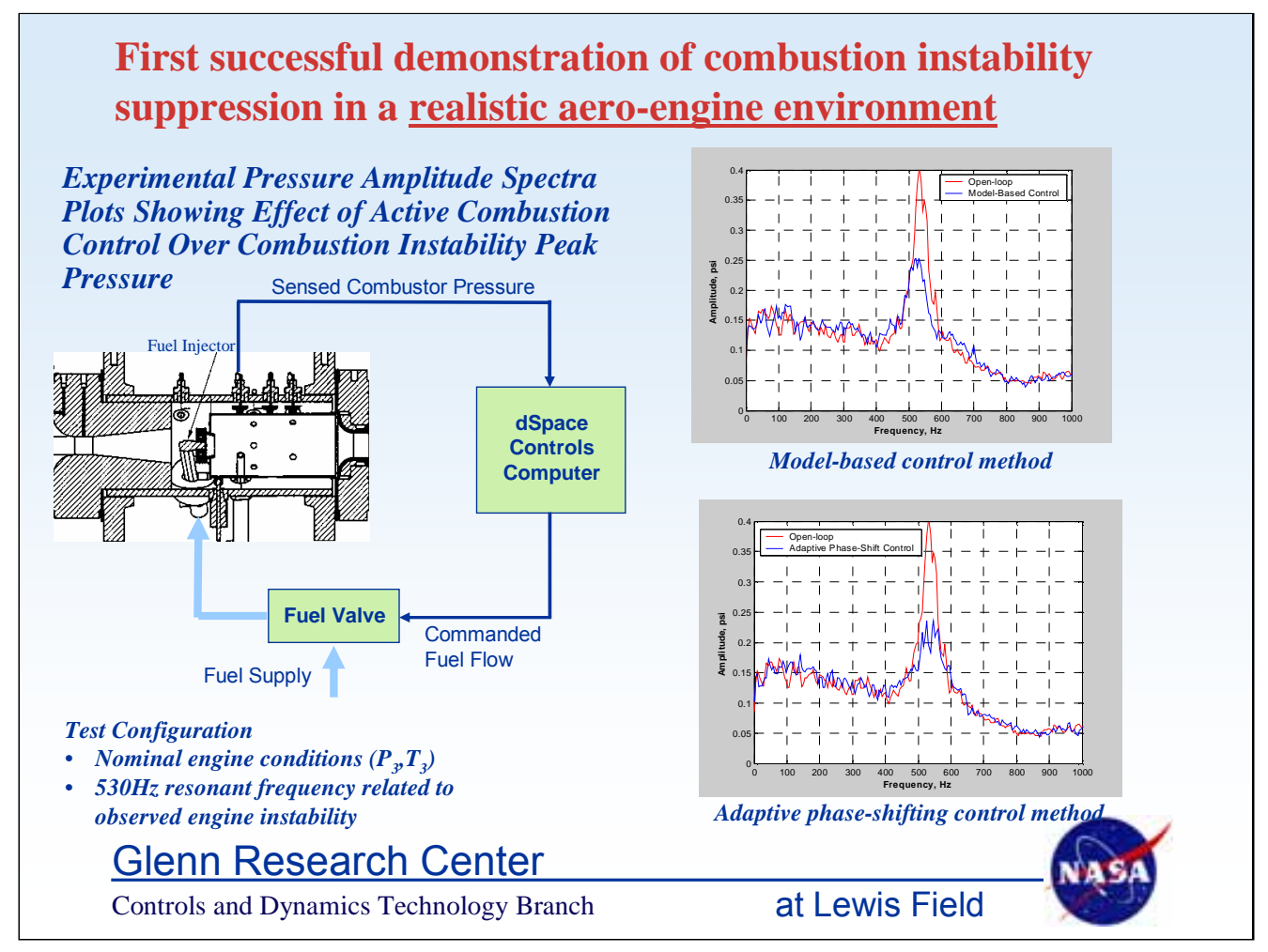

\section{Active Control of Combustion Instability - Recent Results}

In order to achieve closed loop suppression of the combustion instability, two alternative control methods were developed. These control methods were formulated to deal with the large wideband combustor noise, severe time-delay, and randomness in phase associated with the combustor thermo-acoustic pressure oscillations. Both the controllers use the sensed combustion pressure as input and were implemented in a dSpace controls computer.

Both control methods were initially evaluated against reduced order oscillator models of the combustor pressure in order to verify basic functionality. To provide better fidelity validation of controller performance prior to rig testing, both controllers were then tested against a sectored 1-D model of the combustor rig.

The controllers were evaluated on the NASA combustor rig at UTRC, and demonstrated significant reduction in instability magnitude. This is first time such instability suppression has been demonstrated in an "engine like" environment.

Future plans are to investigate the applicability of the instability suppression methodology to advanced combustors being designed by NASA and the aerospace industry.

Ref: Delaat, J.C., and Chang, C.T., “Active Control of High Frequency Combustion Instability in Aircraft Gas-Turbine Engines,” ISABE 2003-1054, proceedings of the International Symposium on Air-Breathing Engines, Cleveland, OH, Sept. 2003. 


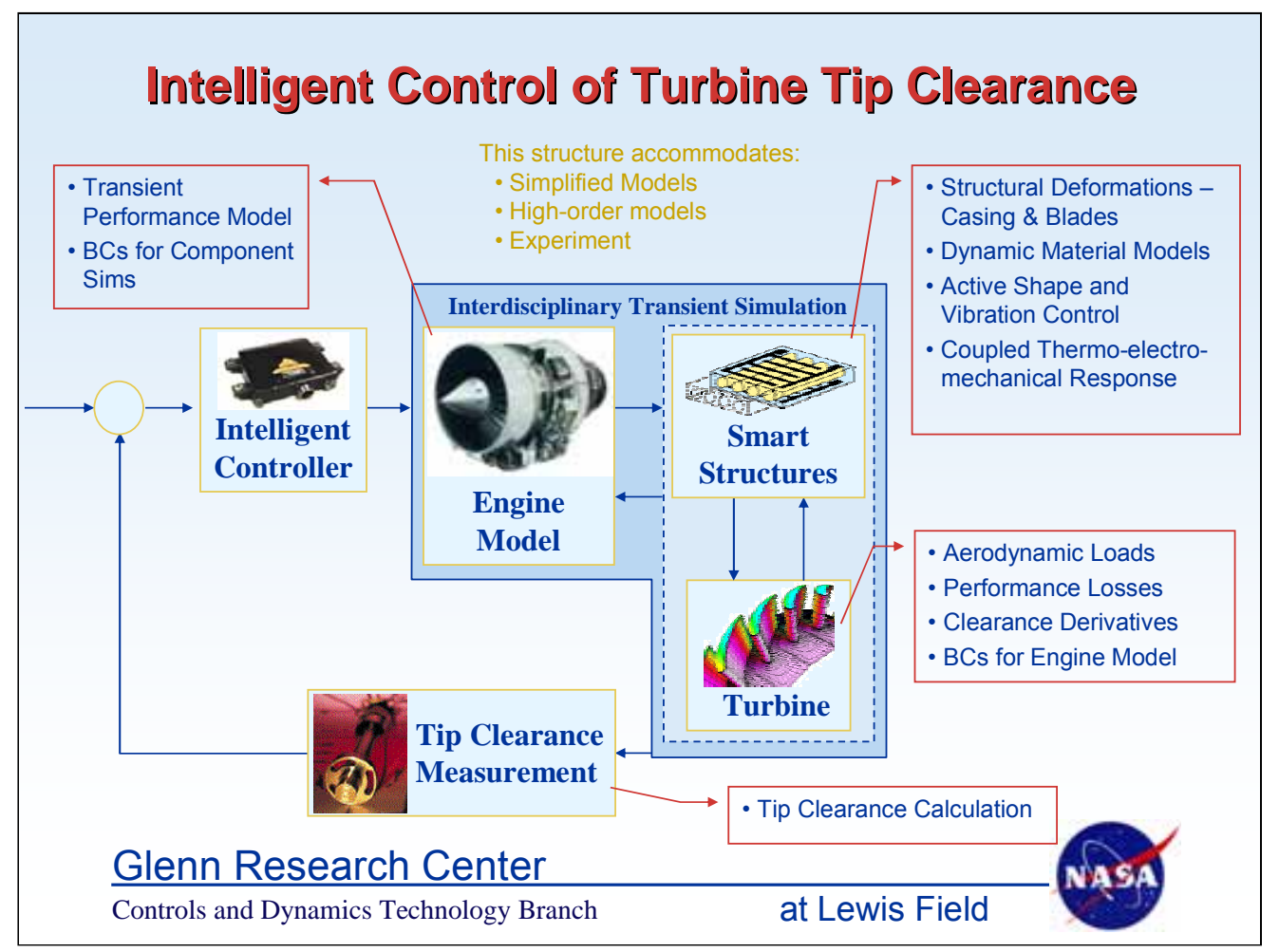

\section{Intelligent Control of Turbine Tip Clearance}

Tight control of the turbine tip clearance at the high pressure turbine is very critical for aircraft engines for both fuel efficiency and on-wing life of the engine. If the clearances are too high, then there is hot gas leakage which is damaging to the engine parts downstream of the hot gas turbine in the hot gas path flow, and also the leakage flow decreases the efficiency of the turbine resulting in higher fuel consumption. If the clearance is too small, then there is the danger of the turbine blades rubbing against the casing. Such rubbing can cause damage to the thermal protective coating on the blades and can cause premature blade damage which would require the engine to be removed from the airplane for turbine blade replacement earlier than scheduled.

During take-off, as the pilot moves the throttle from idle to full power, the rotors accelerate which causes radial expansion of the turbine and blades due to centrifugal forces. Initially the turbine assembly expands faster than the casing due to the centrifugal forces and also due to higher thermal loads because of being directly in the hot gas path. So a "large" cold clearance is built in into the engines to avoid rubbing of the turbine blades against the casing during take-off. During the engine transient, a clearance "pinch point" is reached after which the casing also starts expanding and the steady-state clearance is higher than the minimum reached during the transient. Typically, the bleed from the compressor flow is used to "cool" the turbine casing to manage the stead-state clearance. There is sufficient cushion built in the steady state clearance to allow for engine re-acceleration during flight without the danger of the blades rubbing against the casing.

NASA GRC has initiated research into investigating potential mechanisms for higher bandwidth control of turbine clearance using either mechanical or some sort of smart material based actuation of the casing. 


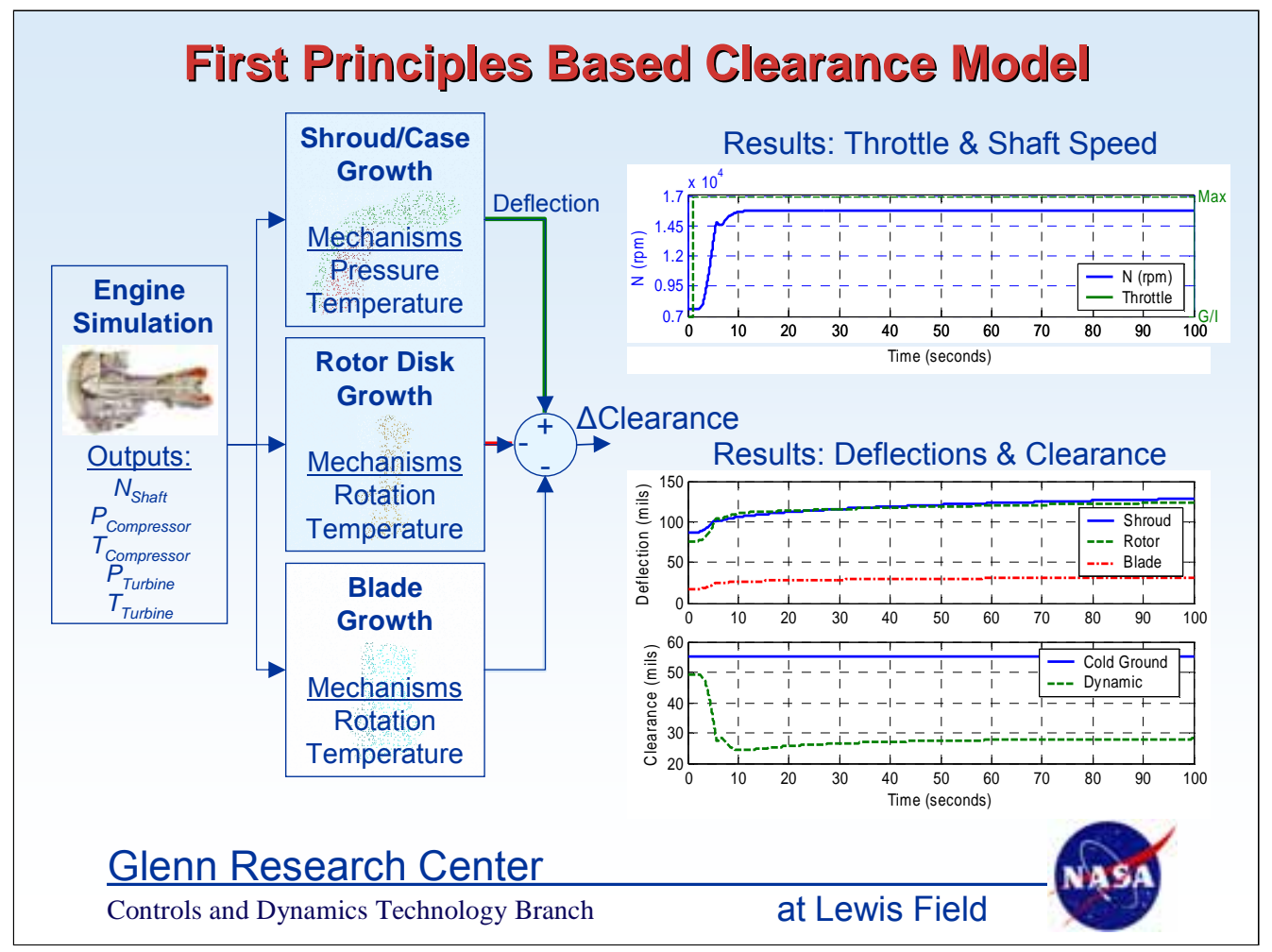

\section{Intelligent Control of Turbine Tip Clearance - Recent Research}

In order to develop actuation and control schemes for intelligent turbine tip clearance control, it is important to have good models of turbine clearance which accurately reflect the transient and steady-state behavior of clearance in response to throttle commands. The aerospace propulsion industry has a wealth of information on turbine clearance based on extensive experimental data, however, this information is considered to be proprietary. Note that currently it is not efficient or economically feasible to measure turbine clearance in flight during engine operation. So the clearance models used by the industry for use of cooling flow based clearance control are based on empirical data which is specific to a particular engine.

NASA GRC has developed a preliminary version of a first-principles based turbine clearance model which is shown in the above figure. This model consists of breaking down the turbine into its three major components - the shroud (or the casing), the rotor disk, and the rotor blades. Transient data from an engine simulation is then used to estimate the growth of each of these components as the engine goes through a transient, and the clearance is calculated based on the difference between the casing growth and that of the rotor and blades. This simple model has been able to capture the essential dynamic behavior of turbine clearance and is being used to determine preliminary specifications for the actuation system which would be needed to make it feasible to provide the desired level of control of clearance. Work is ongoing to further refine the model and integrate it with an engine simulation.

Ref: Melcher, K.J., and Kypuros, J.A., “Toward a Fast-Response Active Turbine Tip Clearance Control," Proceedings of the $16^{\text {th }}$ International Symposium on Airbreathing Engines, Cleveland, OH, Sept. 2003. 


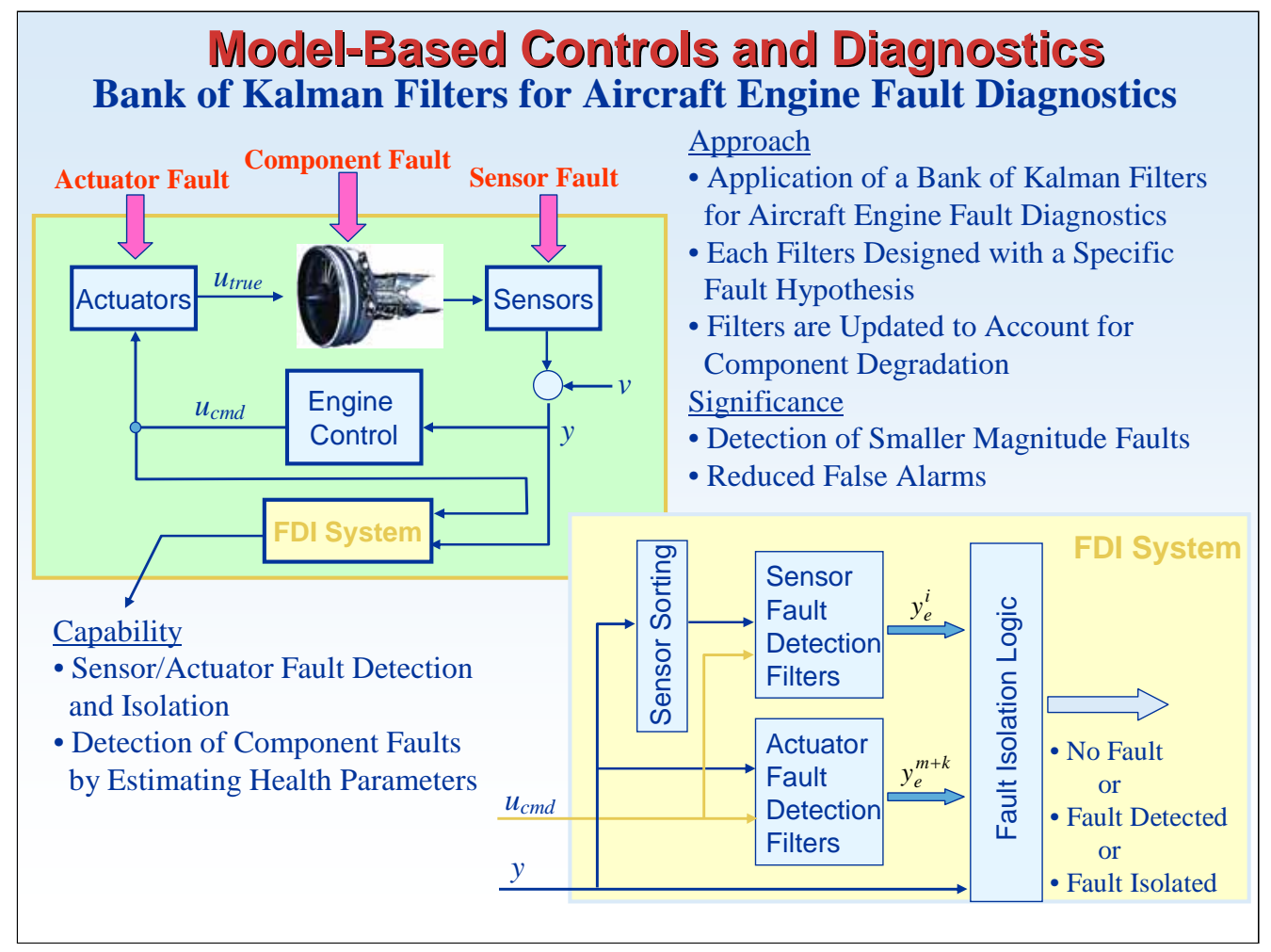

\section{Model-Based Controls and Diagnostics}

Fault detection and isolation (FDI) logic plays a critical role in enhancing the safety and reliability and reducing the operating cost of aircraft propulsion systems. However, achieving the FDI task with high reliability is a challenging problem. Faults may occur in various degrees of severity at various locations; therefore numerous fault scenarios are possible. Moreover, the engine's complex structure and harsh operating environment make interpretation of the available information difficult.

Aircraft operators have used model-based gas turbine engine condition monitoring systems in ground-based applications to trend engine performance from recorded engine measurements. Recent developments in adaptive on-board engine models have now made it possible to consider real-time engine condition monitoring for fault detection and isolation, and optimization of engine control to accommodate off-nominal engine behavior. Model-Based Controls and Diagnostics (MBCD) consists of a real-time on-board aerothermodynamic engine model incorporated into the engine control architecture providing several benefits which include continuous real-time trending of engine health, synthesized sensor values which can be used in sensor validation logic, and estimates of the unmeasurable engine parameters such as thrust and component stability margins which can be used in feedback control logic.

NASA GRC is working in collaboration with General Electric Aircraft Engines (GEAE) to extend MBCD technology to provide prognostic and diagnostic capability and fault accommodation in the propulsion system, thereby preventing or reducing the severity of potentially significant safety failures. Also, GRC is conducting inhouse research on developing an approach to FDI, shown in the above figure, which will be able to reliably distinguish between sensor failures and component faults even as the engine performance degrades due to aging. 


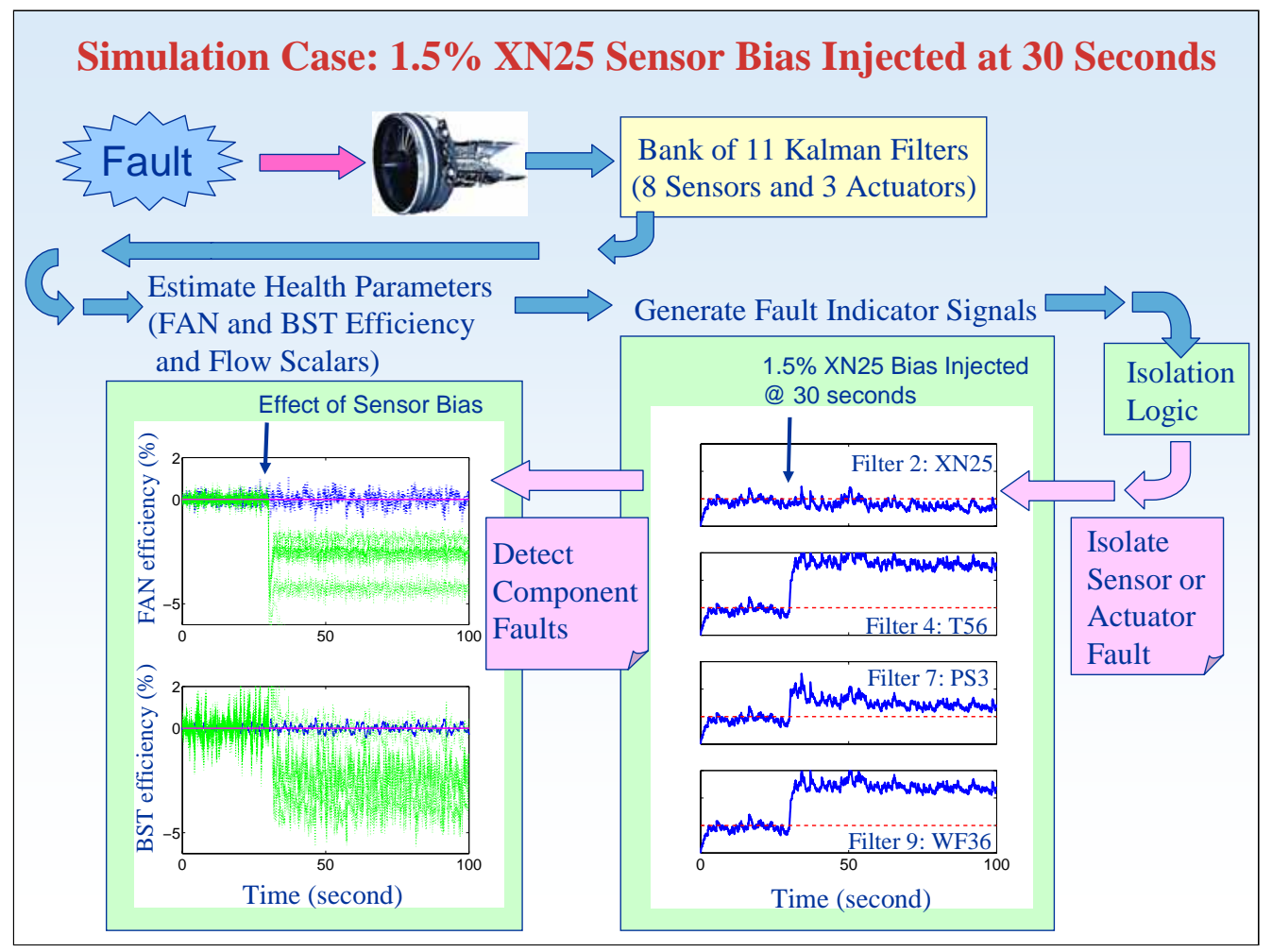

Model-Based Controls and Diagnostics - Recent Results

The GRC developed approach to FDI builds upon the work done by previous researchers in using a Bank of Kalman Filters with each filter designed based on a specific fault hypothesis. The previous approaches focused primarily on identifying sensor faults and could result in a false alarm or missed detection in the presence of actuator faults. Additionally the previous approaches did not address the issue of robustness to engine degradation with usage or component faults due to abrupt changes such as those caused by foreign object damage.

The new FDI approach addresses these issues by incorporating Kalman Filters designed for actuator fault hypotheses into the fault isolation logic and also by updating the parameters in the Kalman Filters based on the engine health parameter trends.

The new FDI approach has been successfully applied to an engine simulation representative of a high performance fighter aircraft engine. The above figure shows an example result from this application. For this particular fault scenario, a 1.5\% bias in the high speed rotor sensor was induced 30 seconds into the simulation. The FDI logic was clearly able to detect that a fault had occurred and was able to isolate it to the high speed rotor sensor, distinguishing it from various other engine health parameter degradation scenarios which would have resulted in the measurements similar to the biased sensor.

Ref: Kobayashi, T., and Simon, D.L., “Application of a Bank of Kalman Filters for Aircraft Engine Fault Diagnostics,” Paper No. GT2003-38550, Proceedings of the International Gas Turbine Institute Turbo Expo 2003, Atlanta, GA, June 2003. 


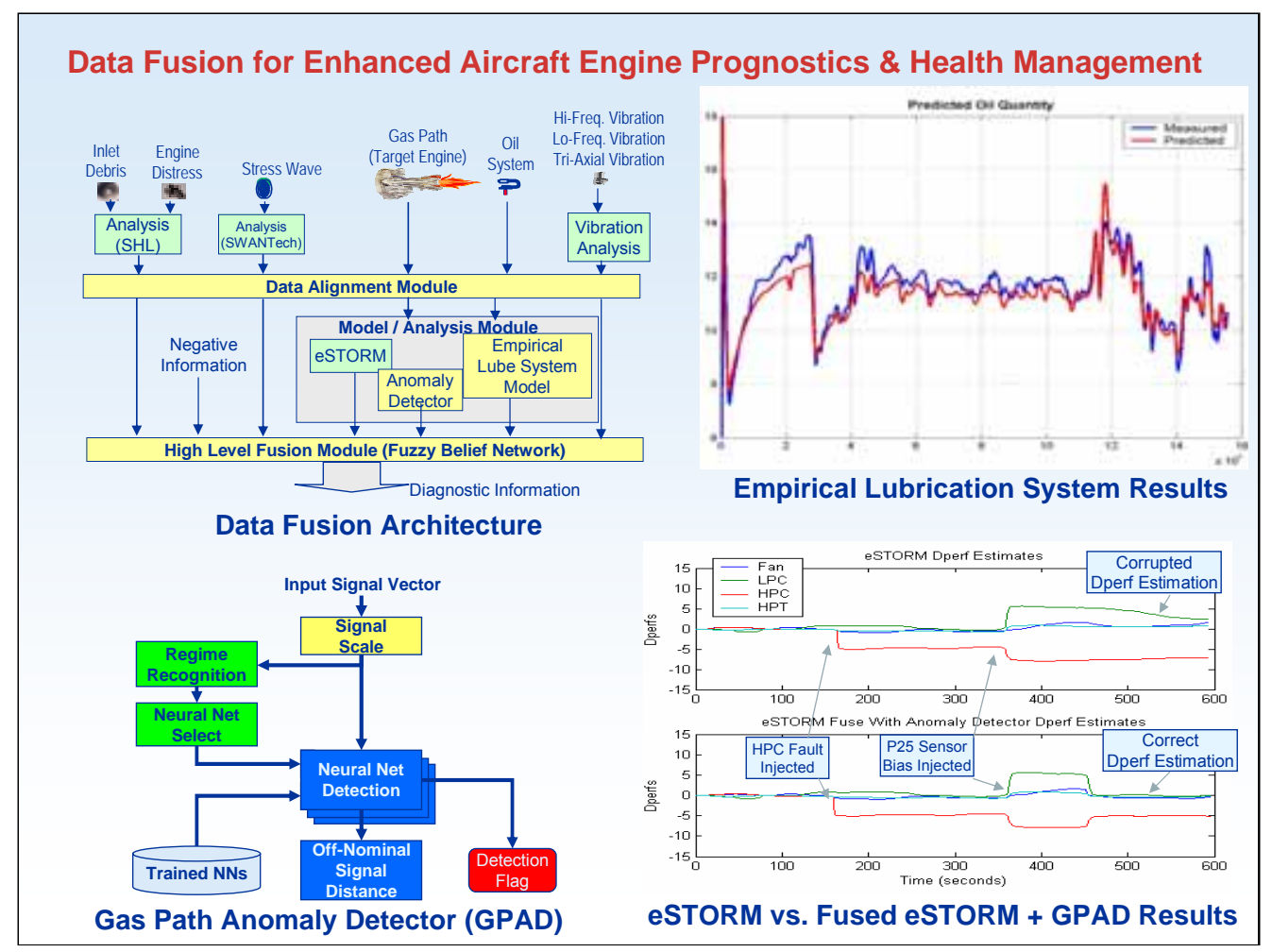

\section{Data Fusion for Enhanced Engine Prognostics and Health Management}

A wealth of aircraft turbine engine data is available from a variety of sources including onboard sensor measurements, operating histories, and component models. Furthermore, additional data will become available, as advanced prognostic sensors are incorporated into next generation gas turbine engine systems. The challenge is how to maximize the meaningful information extracted from these disparate data sources to obtain enhanced diagnostic and prognostic information regarding the health and condition of the engine.

To address this challenge, NASA and Pratt \& Whitney (P\&W) are collaborating to develop Data Fusion technology. Data fusion is the integration of data from multiple sources to achieve improved accuracy and more specific inferences than can be obtained from the use of a single sensor alone. Data fusion will enhance aircraft gas turbine engine Prognostic and Health Management (PHM) system capabilities by reducing false alarms and missed detections, improving engine diagnostics for the accurate isolation of faults, and improving engine prognostics for the accurate assessment of component life consumption and prediction of impending anomalies. This effort is closely coordinated with the C-17 T-1 Aircraft Propulsion Health Management Flight Test Program being conducted by NASA DFRC and flight data collected from the C-17 T-1 is used to demonstrate the technology.

A data fusion architecture has been developed which consists of a Data Alignment module (which uses down-sampling or up-sampling to convert data from disparate sources into a uniform frequency for subsequent analysis), various diagnostic modules (eg. Enhanced SelfTuning On-board Real-time Model (eSTORM), Gas Path Anomaly Detector (GPAD), an empirical lubrication system module, and the high level fusion module. Preliminary results from the application of this architecture have been encouraging.

Ref: Volponi, A.J. et al., "Development of an Information Fusion System for Engine Diagnostics and Health Management," 2003 JANNAF Interagency Propulsion Committee Conference, Colorado Springs, CO, Dec. 2003. 


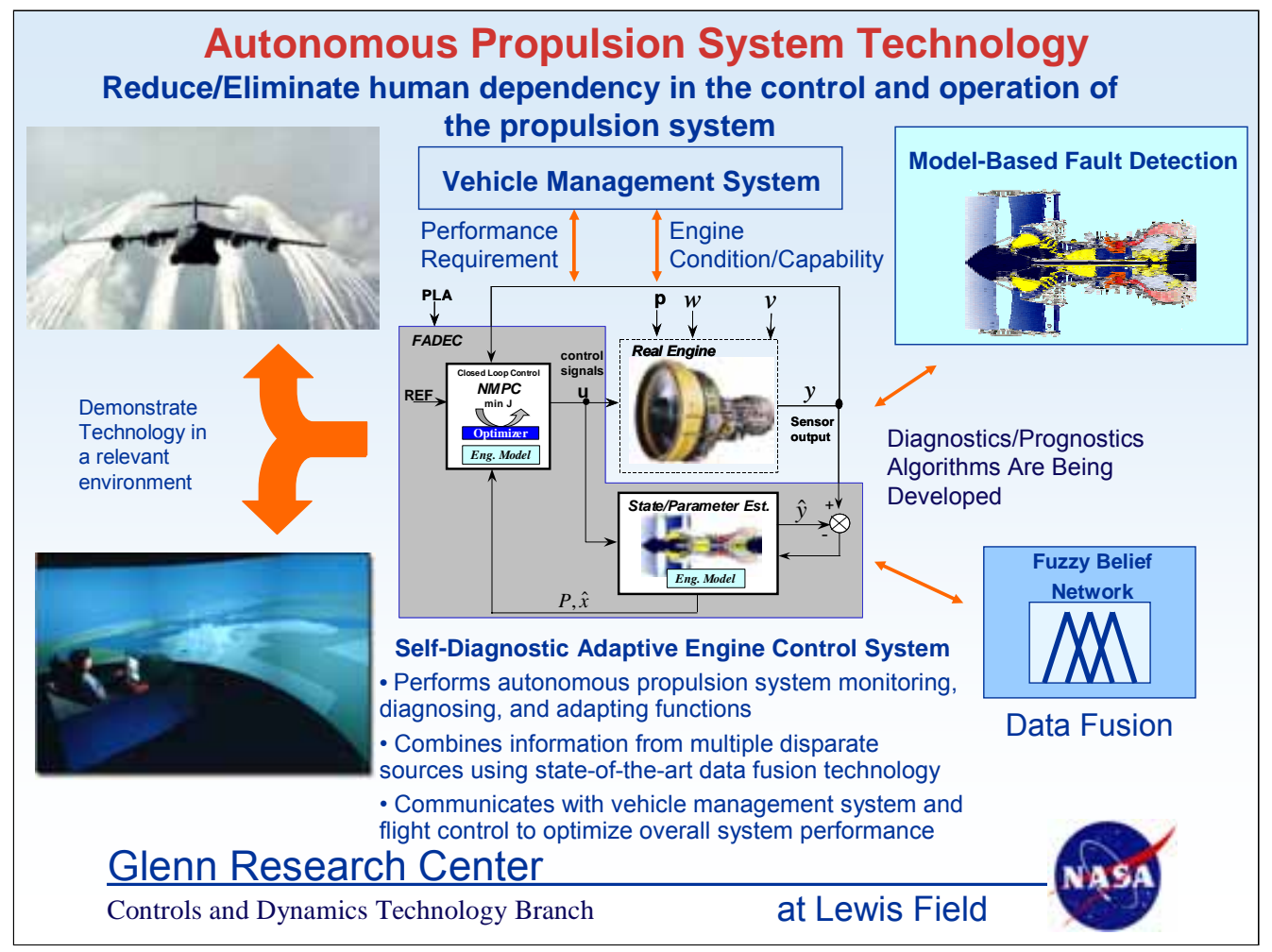

Autonomous Propulsion System Technology

In the current aviation system airplanes, the pilot serves the critical function of integrating the propulsion system control with the flight control. The only exceptions to this are the "autothrottle" system which is deployed as part of the autopilot and is limited to operation at cruise under fair weather conditions, and the "autoland" system which is limited to landing under favorable conditions. Developing technologies for autonomous accomplishment of propulsion system control, diagnostics and prognostics functions is critical for enabling highly or fully autonomous operation of airplanes.

NASA GRC has initiated a new multi-year research effort for developing and demonstrating Autonomous Propulsion System Technology (APST). The APST project will develop and mature propulsion control, diagnostics and prognostics technologies that will enable autonomous operation of the propulsion system based on commands generated from an autonomous flight control. The technologies will be developed with a goal to demonstrate them on a flight test bed which is representative of a large UAV (Uninhabited Air Vehicle) for commercial application. This effort will leverage upon the various other technology development efforts within NASA and other government agencies in the area of propulsion control and diagnostics. 


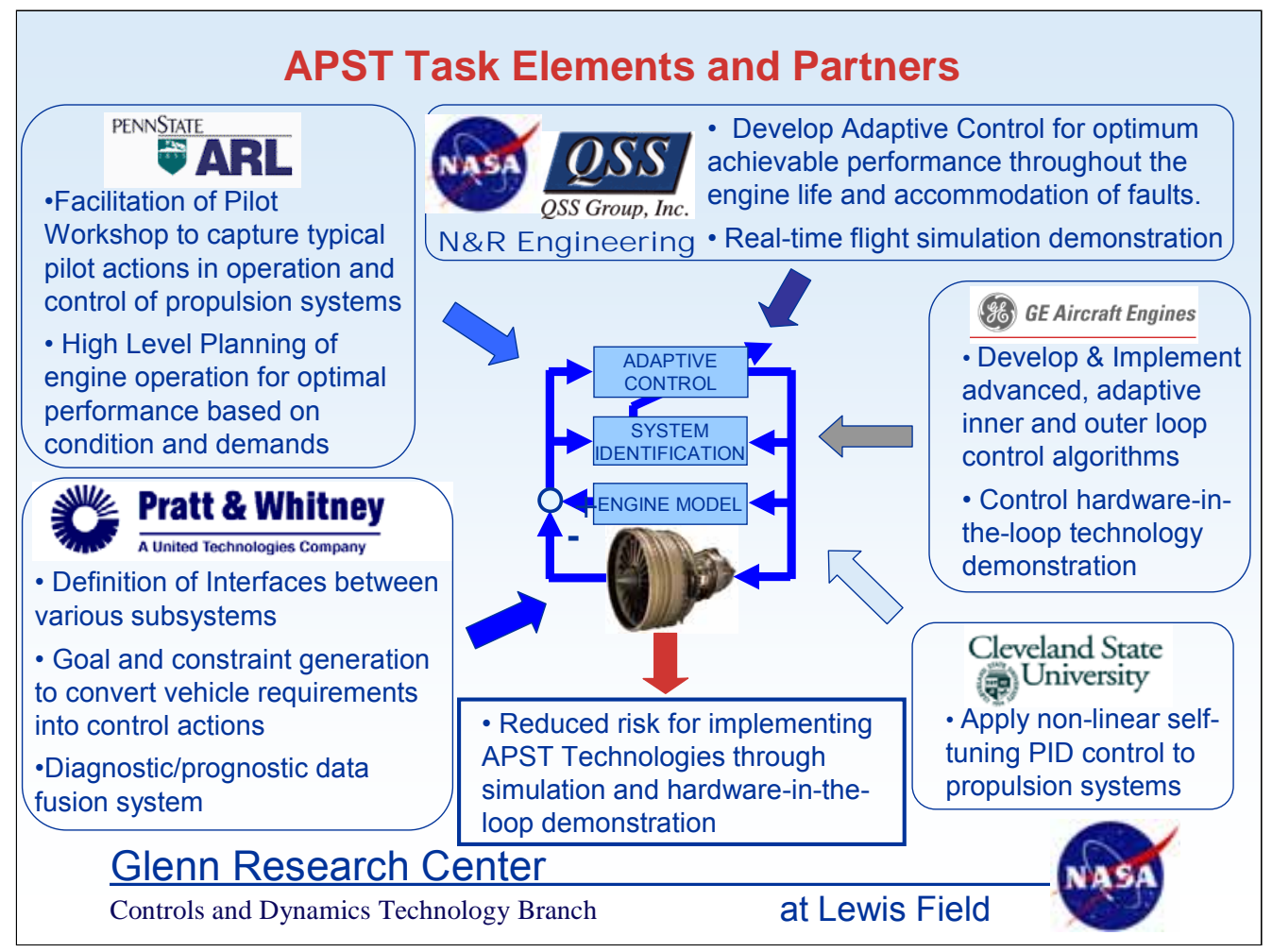

APST Task Elements and Partners

NASA GRC has established an integrated collaborative task plan in partnership with industry and academia to develop and demonstrate the key technologies that are critical for enabling the vision of autonomous propulsion systems.

Working in collaboration with on-site support contractors, NASA researchers are developing adaptive control algorithms to achieve optimum performance even as the engine degrades due to wear and tear. Furthermore, adaptation of control algorithms to maintain performance in the presence of faults or component damage is also being investigated. NASA GRC goal is to demonstrate autonomous operation of the propulsion system in the presence of such faults via real-time human in the loop flight simulation. Some recent results from the in-house research are presented in the reference listed below.

In collaboration with Applied Research Labs of Penn State University, NASA held a pilot workshop to determine propulsion system related pilot workload issues. The findings from this workshop will drive the priority for the technologies developed under APST. Pratt and Whitney is developing the requirements for the interface between the flight and propulsion system and methods to convert high level performance system requirements into control synthesis requirements for on-line adaptation of the controller.

General Electric is developing algorithms for adapting inner and outer loop propulsion control algorithms based on performance requirements and will be demonstrating the autonomous control adaptation using control hardware in the loop simulation.

Ref: Chatterjee, S., and Litt, J.S., “Online Model Parameter Estimation of Jet Engine Degradation for Autonomous Propulsion Control,” AIAA Paper 2003-5425, Guidance Navigation and Control Conf., Austin, TX, Aug. 11-14, 2003. 


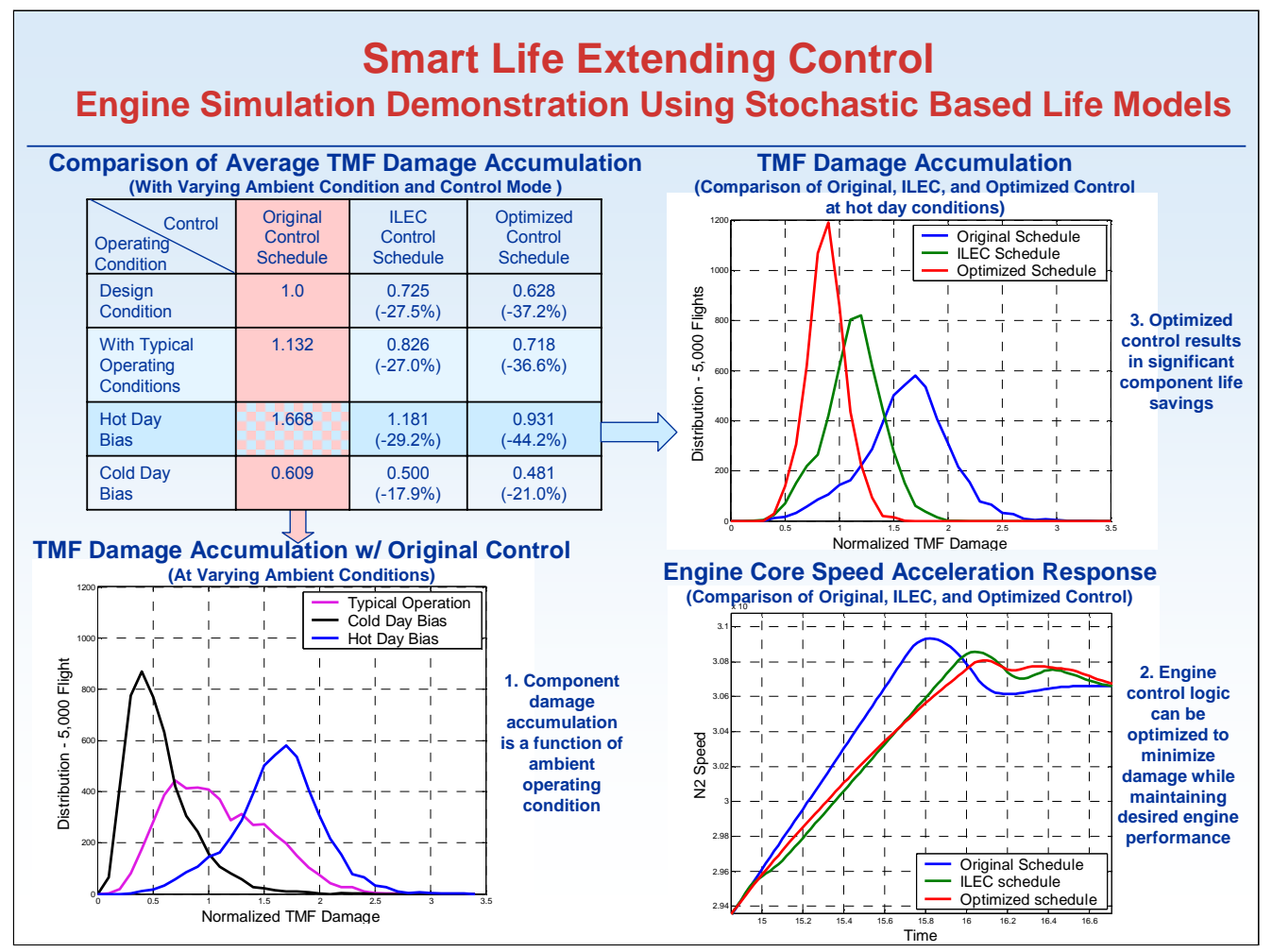

\section{Smart Life Extending Control}

With the recent emphasis on reducing engine operating cost, the industry is interested in developing technologies that will allow the engine and its components to operate longer, thus increasing the time between engine overhauls. NASA GRC pioneered the concept of Life Extending Control and over the years has demonstrated that by using smart acceleration logic for engine control, the thermo-mechanical fatigue damage accumulated during a typical engine acceleration from idle to full power can be significantly decreased without any noticeable loss in engine performance.

Part of life extending control research is to investigate methods to better estimate engine life usage. The commonly used "cycle count" approach does not take the engine operation conditions into account and overly simplifies the calculation of the life usage. Because of this shortcoming in the life calculation, many engine components are regularly pulled for maintenance before the usable life is fully consumed. And, in other cases, if an engine has been running regularly under more severe conditions, it may pose a risk by not being taken out for service at the appropriate time.

Using a closed-loop engine simulation, GRC performed a study based on the Monte Carlo simulation of 5,000 typical flights under various operating conditions and representing typical sensor noise characteristics and engine health parameter variations. The results of this study show that the actual engine life usage can vary drastically depending on operating condition variations, and that optimizing the acceleration schedule can further increase on-wing engine life.

Ref: Guo, T.-H., and Chen, P., "Sensor Based Engine Life Calculation - A Probabilistic Perspective," Proceedings of the 16th International Symposium on Airbreathing Engines, September, 2003, Cleveland, Ohio. 


\section{Modular Aerospace Propulsion System Simulation (MAPSS)}

- Implementation of an advanced turbofan engine component level model in

the Simulink environment and comparison with Fortran simulation

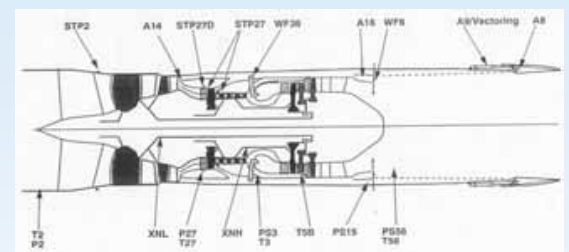

Schematic of Turbo-fan Engine Model

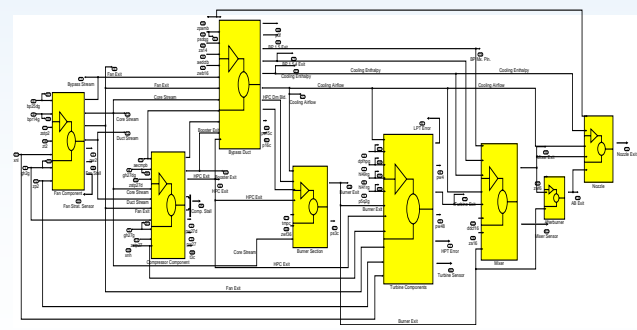

Component Level Model in MAPSS

Glenn Research Center

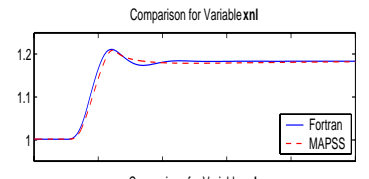

Comparison for Variable xn

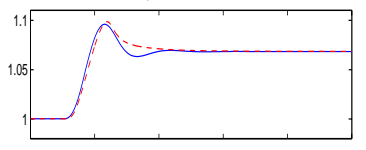

Comparison for Variabletmpc

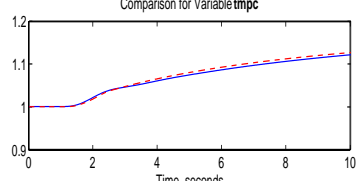

Closed Loop Comparison for PLA 25-30 deg at Lewis Field

\section{Modular Aerospace Propulsion System Simulation (MAPSS)}

Development and validation of the various controls and diagnostics technologies discussed so far requires the availability of a 1-D transient engine simulation which represents the dynamics of the phenomenon being controlled or observed.

Typically, aircraft engine manufacturers develop advanced thermodynamic cycle decks of their production engines which accurately reflect the dynamic behavior of these engines. However, these cycle decks are proprietary in nature, and although NASA is given access to such data on collaborative efforts, NASA cannot share such information with universities or other industry, such as small businesses conducting controls research.

NASA GRC has a Numerical Propulsion Simulation System (NPSS) under development for a period of time which has now become the default simulation system being used by aerospace industry. However, the NPSS system is geared more towards doing cycle analysis or detailed engine component design, and is not "user-friendly" for controls and diagnostics technology development.

To overcome these shortcomings, the Controls and Dynamics Technology Branch has developed a generic simulation of a turbofan engine representative of an advanced fighter aircraft engine, in a graphical simulation environment called Simulink. This graphical environment is the one used by most control designers for development and evaluation of control logic. The Modular Aerospace Propulsion System Simulation (MAPSS) is based on the Component Level Model (CLM) approach used by General Electric Aircraft Engines. The above figure shows that the MAPSS version of the engine simulation compares well with the Fortran code of the original engine simulation. A MAPSS version representing a commercial $90,000 \mathrm{lb}$ thrust engine is currently being developed.

Ref: Parker, K., and Guo, T., "Development of a Turbofan Engine Simulation in a Graphical Simulation Environment,” NASA TM 2003-212543, August 2003. 


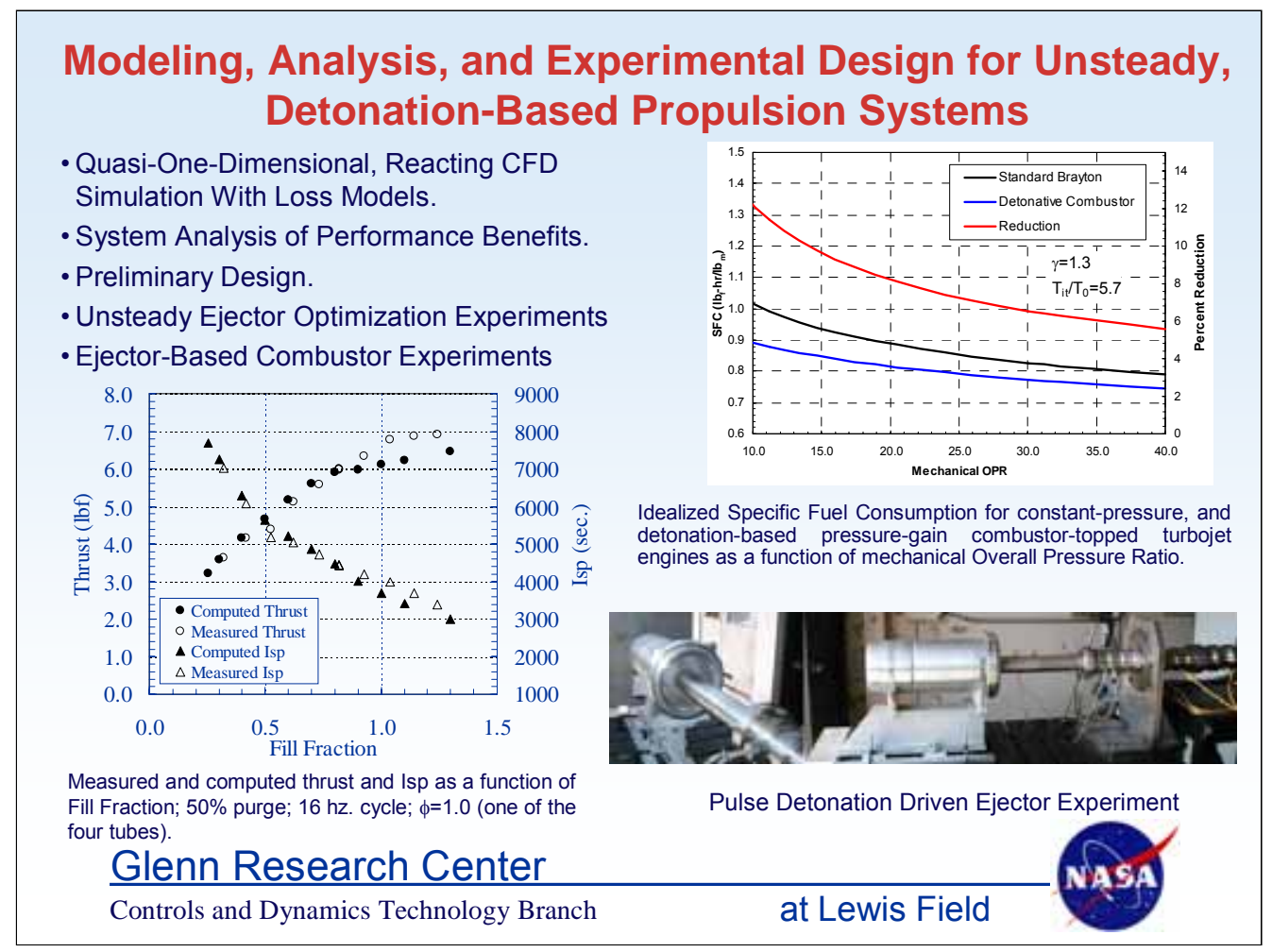

\section{Modeling, Analysis, and Experimental Design for Unsteady, Detonation-Based Propulsion Systems}

GRC has been conducting research in Pulse Detonation Engine (PDE) Technologies because of the potential promise of PDE based propulsion systems to provide significant reduction in specific fuel consumption as compared to traditional turbine based systems. The Controls and Dynamics Technology Branch is supporting this research primarily through modeling and analysis of various PDE based configurations, and doing analytical and experimental investigation on use of ejectors for thrust augmentation.

A Quasi 1-dimensional reacting CFD (Computational Fluid Dynamics) simulation was developed to model a PDE system for which the experimental data was available. The simulation results accurately matched the experimental data thus establishing confidence in the capability of the simulation to be a useful tool in developing the design for the PDE test rig at GRC.

The use of ejectors for augmenting thrust augmentation for unsteady devices was investigated initially using commercially available pulse jet engines. Analytical data using a simulation to predict thrust augmentation with ejectors was correlated with experimental data to develop strategies for optimal design of ejector configurations. Additional experiments using ejectors with other unsteady thrust devices such as a resonance tube were conducted to validate the design of optimal ejector configurations. Work is ongoing on collecting experimental data on ejector performance with the actual GRC PDE system.

Ref: Paxson, D.; Wilson, J.; and Dougherty, K.: Unsteady Ejector Performance: An Experimental Investigation Using a Pulsejet Driver. AIAA Paper 2002-3915, 38 ${ }^{\text {th }}$ Joint Propulsion Conference, Indianapolis, IN, July 2002. 


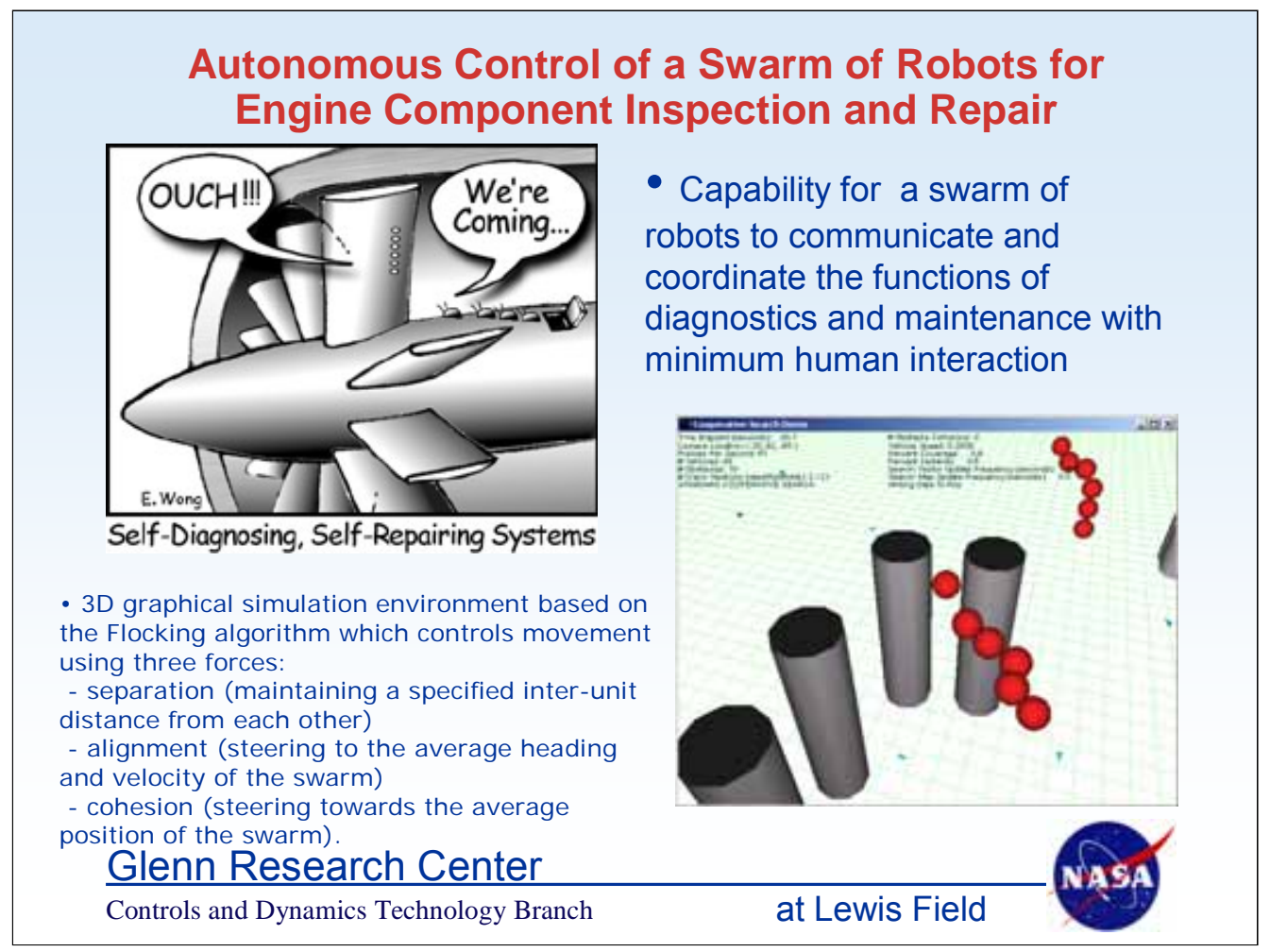

\section{Autonomous Robotic Inspection and Repair of Engine Components}

Modern jet engines undergo regular maintenance inspections for the purpose of detecting evidence of internal distress such as cracking or erosion. The inspection methods range from borescopic on-wing engine internal visual inspection to those requiring full tear down. If much of the inspection and repair that currently requires teardown could be performed on-wing, it would be a boon to the airline industry both in terms of early detection of potential problems and reduced maintenance costs.

NASA GRC has initiated preliminary investigation into the feasibility of creating miniature mobile sensor platforms that can roam the surfaces inside of an engine while it is shut down and be able to perform such inspection and repair functions. It is envisioned that a collaborative swarm of these mobile agents will rove through an engine in a highly coordinated manner, thoroughly searching engine component surfaces to assess damage. Once damage is detected, the location and damage type information will be disseminated, possibly alerting the appropriate group of agents to converge and perform the necessary repairs.

An interactive 3-D graphical simulation testbed environment has been created for implementing, validating, and demonstrating multi-agent collaborative control algorithms. This virtual test bed is being used to develop and explore various cooperative control and search algorithms that will be applicable to a multi-agent onwing jet engine inspection system. At the same time, flexibility will allow the implementation of many other applications within the test bed.

Ref: Litt, J.S., et al., "Cooperative Multi-Agent Mobile Sensor Platforms for Jet Engine Inspection - Concept and Implementation,” IEEE International Conference on Integration of Knowledge Intensive Multi-Agent Systems, Cambridge, MA, Oct. 1-3, 2003. 


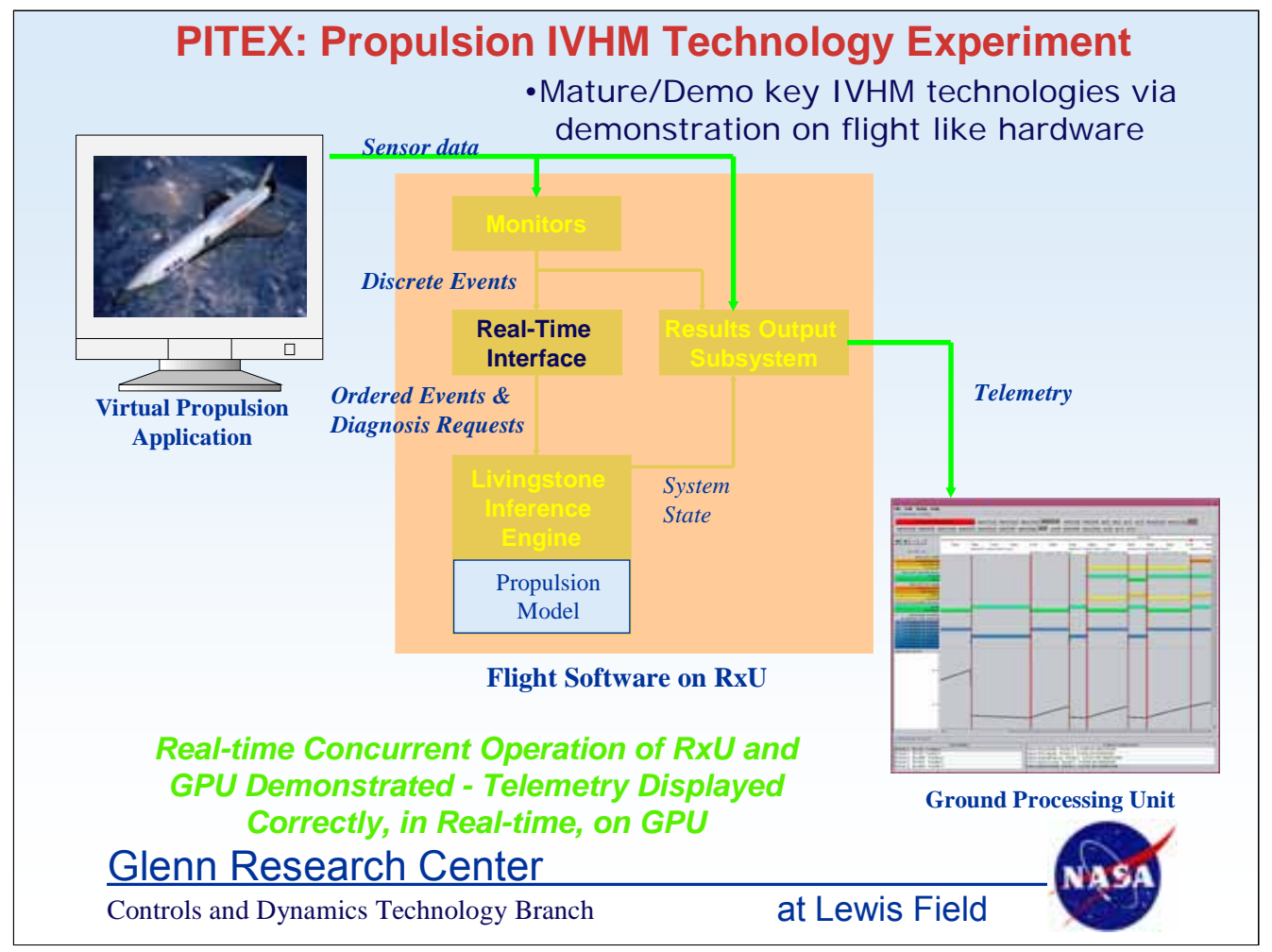

PITEX - Propulsion IVHM Technology Experiment

The Propulsion IVHM Technology Experiment (PITEX) is a joint effort between NASA's Glenn Research Center, Ames Research Center and Kennedy Space Center. It was a key element of a Space Launch Initiative (SLI) Risk Reduction Task performed by the Northrop Grumman Corporation in El Segundo, California. The main objectives of PITEX are the continued maturation of diagnostic technologies that are relevant to 2nd Generation Reusable Launch Vehicle (RLV) subsystems and the assessment of the real-time performance of the PITEX diagnostic solution.

The PITEX effort has considerable legacy in the NASA IVHM Technology Experiment for X-vehicles (NITEX), which was selected to fly on the X-34 sub-scale RLV that was being developed by Orbital Sciences Corporation. The PITEX demonstration system is designed to test a subset of software components from the NITEX flight experiment architecture. The software package consists of the telemetry input system, monitors, real-time interface, Livingstone diagnostic system, results output system, and ground processing unit. The virtual propulsion system simulates the sensor data associated with a particular mission phase and nominal or failure scenario.

PITEX successfully demonstrated real-time model-based fault detection of a virtual main propulsion system. Realistic propulsion system failures involving valves, regulators and sensors were simulated and correctly diagnosed by PITEX.. During testing of the software on flight-like hardware, system resources - CPU and memory - were found to be largely underutilized. This indicated that more complex applications could be handled by the PITEX diagnostic solution.

Ref: Meyer, C., et. al., "Propulsion IVHM Technology Experiment Overview”, 2003 IEEE Aerospace Conference, Big Sky, MT, March 8-15, 2003, Paper\#1481. 


\section{Conclusion}

- Controls and health management technologies play a critical role in making "Intelligent Engines" a reality.

- A multidisciplinary cross-organizational collaborative approach is essential for successful development and demonstration of "Intelligent Engine" technologies

- Critical technologies to be developed for controls and health management of propulsion systems include

- improved understanding and modeling of the dynamic behavior to be controlled or monitored

- robust and adaptive control and diagnostics algorithms

- appropriate sensors and actuators to aid in development and implementation of the overall control system

- A system level approach is essential to ensure that various components of a control or diagnostic system work together as an integrated system to achieve the desired objectives

\section{Glenn Research Center}

\section{Conclusion}

In conclusion, the above figure lists the major challenges currently being faced by the propulsion control design engineers. The Controls and Dynamics Technology Branch at NASA GRC is working in strong partnership with industry, academia and other government agencies to develop the propulsion control and health management technologies that will help make the vision of "Intelligent Engines" a reality. Our objective is to use the public resources in a most efficient manner to meet the aggressive goals for civil aviation that have been set by the administrator in the latest strategic plan for NASA, and to ensure that our activities are aligned with the goals of the NASA Themes that we participate in. 
Public reporting burden for this collection of information is estimated to average 1 hour per response, including the time for reviewing instructions, searching existing data sources, gathering and maintaining the data needed, and completing and reviewing the collection of information. Send comments regarding this burden estimate or any other aspect of this collection of information, including suggestions for reducing this burden, to Washington Headquarters Services, Directorate for Information Operations and Reports, 1215 Jefferson Davis Highway, Suite 1204, Arlington, VA 22202-4302, and to the Office of Management and Budget, Paperwork Reduction Project (0704-0188), Washington, DC 20503.

\begin{tabular}{|l|l|l}
\hline 1. AGENCY USE ONLY (Leave blank) & $\begin{array}{c}\text { 2. REPORT DATE } \\
\text { February } 2004\end{array}$ & $\begin{array}{c}\text { 3. REPORT TYPE AND DATES COVERED } \\
\text { Technical Memorandum }\end{array}$ \\
\hline
\end{tabular}

\section{TITLE AND SUBTITLE}

Controls and Health Management Technologies for Intelligent Aerospace Propulsion Systems

6. AUTHOR(S)

Sanjay Garg

\section{FUNDING NUMBERS}

Cost Center 2255000001

8. PERFORMING ORGANIZATION REPORT NUMBER

E-14354

National Aeronautics and Space Administration

John H. Glenn Research Center at Lewis Field

Cleveland, Ohio 44135-3191

10. SPONSORING/MONITORING AGENCY REPORT NUMBER

National Aeronautics and Space Administration

Washington, DC 20546-0001

NASA TM-2004-212915

AIAA-2004-0949

\section{SUPPLEMENTARY NOTES}

Prepared for the 42nd Aerospace Sciences Meeting and Exhibit sponsored by the American Institute of Aeronautics and Astronautics, Reno, Nevada, January 5-8, 2004. Responsible person, Sanjay Garg, organization code 5530,

216-433-2685.

12a. DISTRIBUTION/AVAILABILITY STATEMENT

12b. DISTRIBUTION CODE

Unclassified - Unlimited

Subject Categories: 07 and 63

Distribution: Nonstandard

Available electronically at http://gltrs.grc.nasa.gov

This publication is available from the NASA Center for AeroSpace Information, 301-621-0390.

13. ABSTRACT (Maximum 200 words)

With the increased emphasis on aircraft safety, enhanced performance and affordability, and the need to reduce the environmental impact of aircraft, there are many new challenges being faced by the designers of aircraft propulsion systems. The Controls and Dynamics Technology Branch at NASA (National Aeronautics and Space Administration) Glenn Research Center (GRC) in Cleveland, Ohio, is leading and participating in various projects in partnership with other organizations within GRC and across NASA, the U.S. aerospace industry, and academia to develop advanced controls and health management technologies that will help meet these challenges through the concept of an Intelligent Engine. The key enabling technologies for an Intelligent Engine are the increased efficiencies of components through active control, advanced diagnostics and prognostics integrated with intelligent engine control to enhance component life, and distributed control with smart sensors and actuators in an adaptive fault tolerant architecture. This paper describes the current activities of the Controls and Dynamics Technology Branch in the areas of active component control and propulsion system intelligent control, and presents some recent analytical and experimental results in these areas.

14. SUBJECT TERMS

Adaptive control; Turbojet engine control; Air breathing engines; Gas turbine engines

17. SECURITY CLASSIFICATION OF REPORT

Unclassified

\section{SECURITY CLASSIFICATION OF THIS PAGE \\ Unclassified}

19. SECURITY CLASSIFICATION OF ABSTRACT

Unclassified
15. NUMBER OF PAGES

29

16. PRICE CODE

\section{LIMITATION OF ABSTRACT}

